\section{The First 10 Years}

Albert Einstein was quoted as saying that time is an illusion. As I gather my thoughts to write this editorial, his statement rings true.

It seems like only yesterday that Thomas Jefferson University's Board of Trustees unanimously approved a plan to create the nation's first school of population health. It happened in July of 2008; yet, the powerful emotions I felt resurface when I recall that day. I had dedicated my career to making our nation's healthcare system safer, more costeffective and more equitable. The new school could open up unforeseen opportunities for advancing population health. We could help chart a new course for health education and research, but it wouldn't be easy. Population health was a relatively unfamiliar term at that time, and we were faced with "reinventing the wheel" as we sought to create innovative academic programs, develop curricula, and acquire certification.

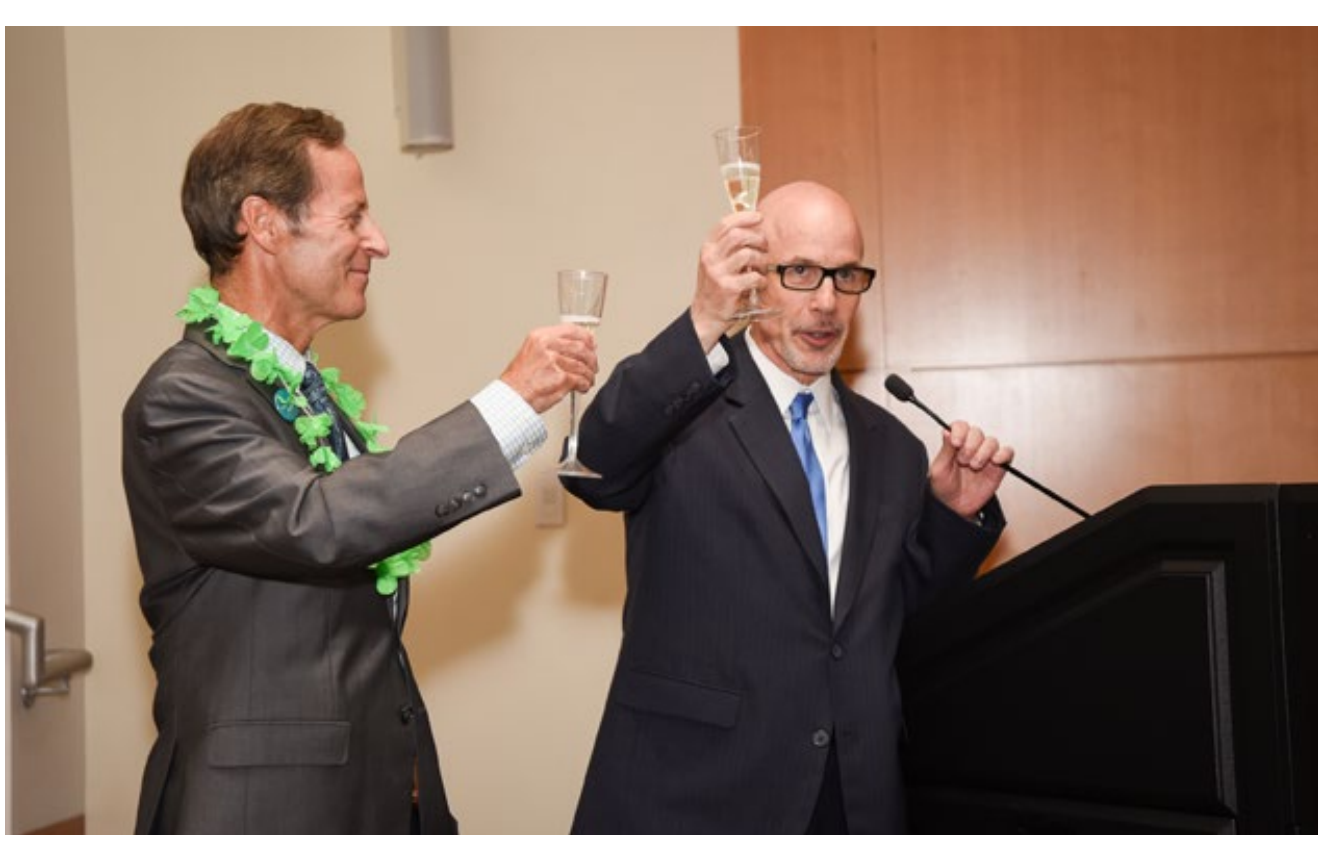

In the 10 years since the school's founding, the healthcare landscape has undergone considerable change. The Affordable Care Act became law and continues to ensure that millions more Americans have health insurance coverage despite multiple Congressional attempts at repeal. Heightened standards for electronic health records have paved the way for generating "big data" that makes correlations possible at the population level. New drugs have been launched (the number of new FDA-approved drugs doubled between 2016 and 2017 making it possible to prevent, manage and cure previously intractable conditions. It should come as no surprise that traditional education is finding it difficult to keep pace with the changes in this rapidly evolving and highly complex health system. In fact, healthcare professionals who completed their training a mere 5-10

Continued on page 2
The First 10 Years.

Jefferson Emergency Opt-Out

Program: Working to Address Public

Health within Acute Care

One Block at a Time: Improving Lives through Urban and Social Innovation in Philadelphia

Signs of Humanity: A

Qualitative Exploration of the

Panhandling Experience

Public Health on the Front-Line:

Bridging the Gaps

Service Learning for Public

Health Education: A Window

Into the World Next Door

Nexus Maximus 2018

Multidisciplinary learning linking

Community Health and Innovation.......11

The Muller Institute for Senior

Health: Innovative Programs to

Address Aging.....

Navvis and TJU Establish Professorship in Population Health

Implementing Jefferson Health's

Electronic Clinical Quality Metric

Reporting

An ACE for South Philly Acute Care for the Elderly (ACE) unit makes all the difference at Methodist Hospital

Meet the JCPH Health Economics

Outcomes Research (HEOR) Fellows .. 18

\section{Announcements \& Upcoming Events}

Population Health Colloquium............... 13

Upcoming Population Health Forums ...14

JCPH 2018 Awards

What's Next for Population

Health Matters?

In the News

JCPH Publications .......................................21

JCPH Presentations. 21 
years ago find that they lack the necessary leadership skills to be successful in such a dynamic environment.

Here at what is now the Jefferson College of Population Health (JCPH), the decade seems to have flown by as we achieved - and often surpassed - ambitious goals. Faculty and staff defined - and redefined - what it means to study population health; launched a doctoral program and 6 masters and certificate programs within the discipline; and maintained one of the nation's premier Health Economics and Outcomes Research Fellowship programs (with more than 50 Fellows trained to date in collaboration with industry partners). Academic programs that were specifically designed for experienced health care professionals (eg, practicing physicians, pharmaceutical executives, community health organizers) have enabled students to develop expertise in healthcare quality, data analytics, health policy, social determinants of health, and operational efficiency.

In addition to meeting the considerable challenges of establishing robust academic programs in emerging fields of study, JCPH developed a Center for Population Health Innovation (CPHI) to facilitate communication and interaction between external stakeholders and the College and to provide ongoing training, development and support for individuals at all levels of learning. The CPHI works with diverse stakeholder groups to identify needs, catalogue available resources, develop interventions, and test solutions. The Center augments formal academic programs by offering learning opportunities in multiple formats and contexts (eg, conferences, webinars, workshops, "boot camps," and leadership retreats) in addition to organizing and convening stakeholder meetings, expert advisory panels, policy discussions, and monthly Population Health Forums. $\mathrm{CPHI}$ also provides editorial services to support the creation of articles, special supplements, and textbooks.

Reflecting on the College's first decade, several things stand out for me.

- The Hearst Health Prize for Excellence
in Population Health: Through an
industry partnership with Hearst
Health, JCPH created the framework,
criteria and evaluation process for
this national competition. Our faculty
review applications and the top-scoring
submissions are forwarded to a national
panel of expert judges. Now in its fourth
year, the competition has received more
than 350 submissions and over $\$ 350,000$
has been awarded to population health
initiatives that make a positive difference
in the lives of Americans.
- In addition to the CPHI, JCPH launched
two freestanding centers for population
health research in Pennsylvania; one

focused on urban/suburban issues and the other focused on rural health.

What lies ahead as time slips into the future? Willie H. Oglesby, PhD, MSPH (Associate Dean for Academic \& Student Affairs) feels that we've only scratched the surface. His teaching team looks forward to expanding educational programming and curricula and growing an international network of healthcare reformers. Associate Dean for Strategic Development and Executive Director of the CPHI, Alexis Skoufalos, EdD, believes that we are only beginning to reframe our perspective on health and shift our focus to upstream factors and social determinants.

If time is illusory, I am grateful that we took a brief "time out" in July of 2018 to celebrate this remarkable 10-year journey before we get back to work.

JCPH 10th Anniversary Report: https://jdc.jefferson.edu/hpreports/5/

JCPH 10th Anniversary Video: https://www.youtube.com/

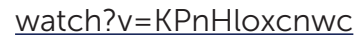

\section{David B. Nash, MD, MBA}

Dean

Jefferson College of Population Health David.Nash@Jefferson.edu

\section{Jefferson Emergency Opt-Out Program: Working to Address Public Health within Acute Care}

In the 2008 report on HIV and AIDS in the City of Philadelphia, then-Heath Commissioner Donald Schwarz, MD, MPH, MBA, and team noted that 2007 marked the largest number of people living with HIV/ AIDS in the city's history. The rate of HIV infection in Philadelphia was estimated to be 114 per 100,000 population, reflecting a rate five times greater than that of the United States (national rate of infection the same year was 23 per 100,000 population). ${ }^{1}$ Moreover, it was estimated that more than $25 \%$ of those with HIV were unaware of their diagnosis. This data, combined with the Revised Recommendations for HIV Testing of Adults, Adolescents and
Pregnant Women in Heath Care Settings released in 2006, further prompted even greater city-wide efforts in HIV screening and early diagnosis. ${ }^{2}$ Both the Centers for Disease Control and Prevention (CDC) and Philadelphia Department of Public Health recognized Emergency Departments as ideal sites for routine HIV testing.

The Thomas Jefferson University Hospital (TJUH) Emergency Department began HIV screening in 2008. With funding from the AIDS Activity Coordinating Office (AACO), the program initially consisted of a single counselor administering Point of Care (POC) HIV tests in the Emergency
Department (ED). With this single tester, the TJUH ED implemented opt-in testing, where patients were individually approached and consented for HIV screening in the ED, and thus became perhaps the first in Philadelphia to do so. These efforts included a developed linkage to care process with Jefferson Division of Infectious Diseases. In 2014, the Emergency Department secured a grant through the Frontlines of Communities in the US (FOCUS) program of Gilead Sciences. FOCUS funding supported program expansion and development of a sustainable infrastructure to promote ongoing HIV screening, with increased 
emphasis on blood-based testing using 4th generation testing technology, in the Emergency Department.

With the financial support for expansion of services and bolstered by policy changes for appropriate testing consent on the national, state and institutional levels, the Emergency Opt-Out Program was born. We implemented an opt-out model of testing where patients were informed that they would be tested for HIV unless they specifically declined, with a focus on a CDC-recommended cohort of patients ages 18 to 65 years old. The program further expanded to involve Methodist Hospital Division Emergency Department in 2015.

The ED nurses and medical technicians have been the crucial backbone to the program throughout, as key drivers in informing patients of the opt-out process and initiating the testing protocol. The linkage to care process was further streamlined to ensure greater patient-centeredness and ease for those newly diagnosed.

In total, the Emergency Opt-Out Program has tested nearly 43,000 patients and has newly diagnosed 194 people with HIV. From 2008-2013, more than 7,000 HIV tests were performed, yielding 40 newly diagnosed patients with HIV. From 2014 to June 2018, more than 35,000 total HIV tests were done, yielding 154 new HIV diagnoses. Nearly $20 \%$ were newly diagnosed with acute HIV (infected within the previous 14-21 days) and $80 \%$ were diagnosed with chronic or established HIV. Of those newly diagnosed, $80 \%$ identified as male, $70 \%$ were African American/black, 48\% identified as men who have sex with men (MSM) and $36 \%$ identified as heterosexual, $23 \%$ were $18-25$ years at diagnosis, $32 \%$ were $26-35$, $20 \%$ were $36-45$, $15 \%$ were $46-55$, and $9 \%$ were 56-65. Working closely with Jefferson Division of Infectious Diseases, the program has successfully linked more than $80 \%$ to specialty care.

As opt-out testing steadily became more routinized in our EDs, Jefferson Emergency Opt-Out programmatic efforts expanded to address other facets of the HIV care continuum. Beginning in 2017, we implemented efforts for re-engagement to care for known HIV-positive patients who had fallen out of HIV treatment. Once identified, we facilitated linkage and reengagement for those amenable within Jefferson Health for primary and specialty care. Finally, in order to further decrease
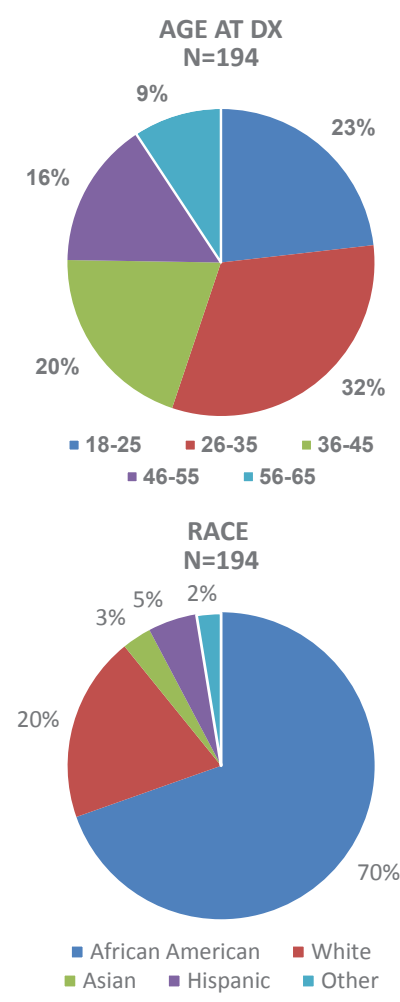
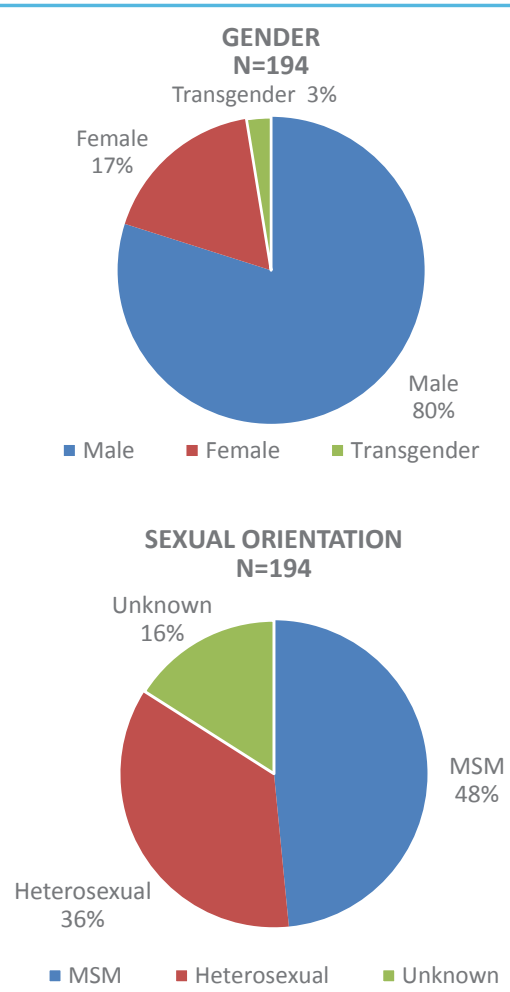

HIV Testing Growth Jefferson EDs

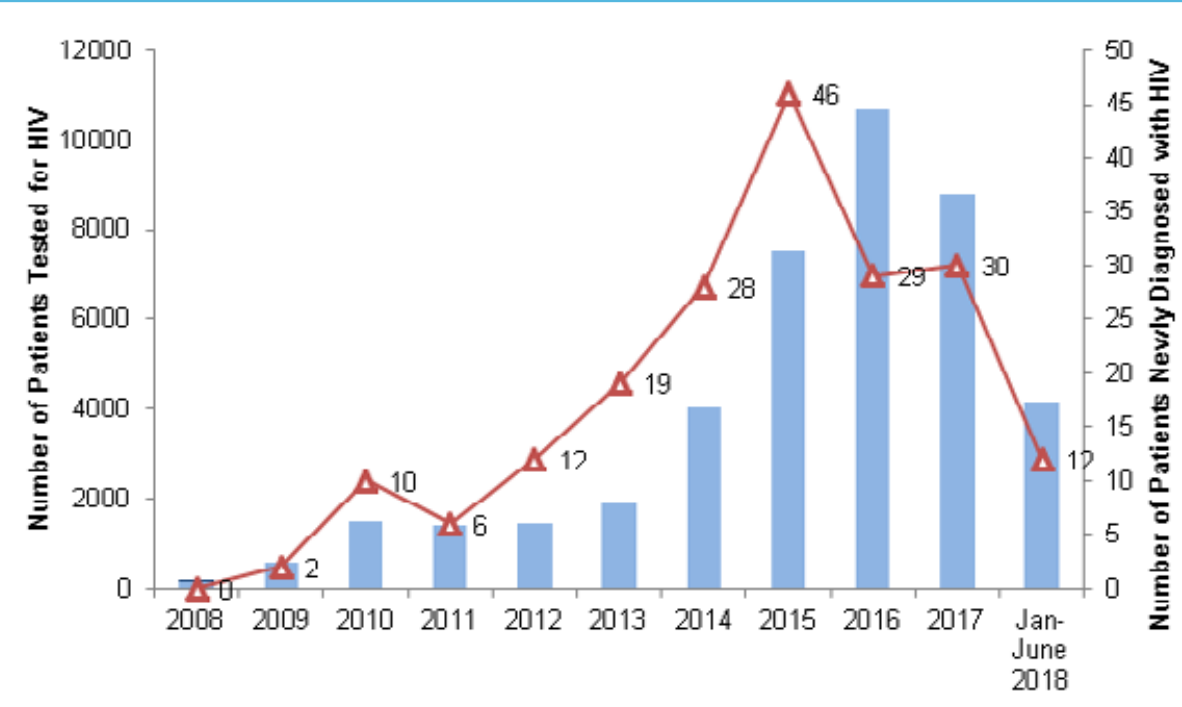

Total Tecto (POC and Lab testo) $\triangle$ Patiento Nowly Diagnoced (POC and Lab tecto)

risk of transmission and new infection, we worked to identify at-risk individuals who tested negative for HIV to focus education and counseling efforts around PreExposure Prophylaxis (PReP) services.

While our clinical efforts have been focused on patients and families, the Emergency Opt-Out Program also aligned academic efforts with the mission of Thomas Jefferson University. We implemented HIV educational and awareness campaigns for ED and hospital staff. We developed interdisciplinary collaborations with other clinical departments within Jefferson Health, including Jefferson Division of Infectious Diseases, Jefferson Obstetrics and Gynecology Associates (JOGA), Jefferson Women's Primary Care, and Jefferson Division of Geriatrics and Palliative Care. We worked to increase community awareness of Jefferson services and advocacy through collaborations with various community organizations. 
the impact EDs can have on the health and wellbeing of a patient and their community through surveillance and patient-centered interventions. It further reflects the significant role EDs can play in reducing disparities in early diagnosis and care.

Since 2008, more than $\$ 1.5$ million has been invested in Jefferson EDs to design and implement an HIV screening process within the acute care space. The Emergency OptOut Program was developed to routinize HIV screening in the ED with a constant eye to sustainability. Federal programs, such as Ryan White funding, enable newly diagnosed patients to become eligible for insurance coverage. The return on investment for this and other similar programs ${ }^{4}$ from the ED is compelling, in terms of life expectancy, quality-adjusted life years (QuALY), and reduced risks of transmission and incidence of HIV in the community, as well as on the health system as a whole. Through increased referrals to internal specialty services and greater insurance coverage and reimbursements for chronic disease management, the Emergency Opt-Out Program could potentially fund itself with appropriate billing and capture. Jefferson Emergency Departments have been on the forefront of implementing programs that address population health needs. Unfortunately, funding for this program is ending, but it is hoped that the Opt-Out model can be implemented again in the future. Its impact on Jefferson patients and the community is very promising.

\section{Priya E. Mammen, MD, MPH \\ Director of Public Health Programs and \\ Clinical Associate Professor \\ Department of Emergency Medicine \\ Sidney Kimmel Medical College at Thomas \\ Jefferson University \\ priya.mammenajefferson.edu}

\section{With contribution from:}

Madalene Zale, MPH
Program Manager
Emergency Opt-Out Program
Department of Emergency Medicine
Thomas Jefferson University Hospital
Madalene.Zale@Jefferson.edu
Madalene is a recent graduate of the JCPH
MPH program.
Jillian Benedetti
MPH Candidate and Student Intern
Jefferson College of Population Health
Jillian.Benedetti@Jefferson.edu

\section{REFERENCES}

1. Philadelphia Department of Public Health. AIDS Activities Coordinating Office Surveillance Report, 2007. Philadelphia, PA: City of Philadelphia; September 2008

2 Centers for Disease Control and Prevention. Revised Recommendations for HIV Testing of Adults, Adolescents and Pregnant Women in Health Care Settings. MMWR. 2006; 55(RR14);1-17.

3 Philadelphia Department of Public Health. AIDS Activities Coordinating Office Surveillance Report, 2016. Philadelphia, PA: City of Philadelphia; September 2017.

4 Mammen PE, Sanaman P, Perrone, J. Grassroots efforts led by emergency physicians to mitigate the escalating opioid epidemic, circa 2012. Care redesign case study. NEJM Catalyst. April 25, 2018.

\section{One Block at a Time: Improving Lives through Urban and Social Innovation in Philadelphia}

\author{
The Built Environment Matters \\ An increasing body of evidence suggests \\ that public health is impacted by the \\ quality of the built environment. ${ }^{1}$ \\ The general definition of the built \\ environment usually refers to the micro- \\ and macro-scale of the human-made \\ environment including buildings, parks, \\ transportation and infrastructure systems.
}

It encompasses all spaces and places in which people live, work and play. ${ }^{2}$ More recently, public health has expanded the definition to include access to healthy food, community gardens, access to education and health care.

While major public health issues in the developing world include infectious diseases, overcrowded urban areas or unsanitary conditions, public health issues are mostly associated in the Western societies with chronic diseases such as diabetes, cancer, coronary vascular disease and asthma. Sedentary life style, coupled with automobile-dependent environments in our neighborhoods and cities, the lack of sidewalks and destinations to which to 
walk, and other environmental factors (such as air-pollution and environmental toxins) contribute to physical inactivity and to the rise of chronic diseases. Research has shown that health-promotive environments (neighborhoods that include a mix of residential areas, work and educational places and retail with high levels of proximity, green spaces and good street connectivity) encourage physical activity and lead to better health outcomes. ${ }^{3}$

\section{The Current State in Philadelphia}

Philadelphia has some of the nation's worst health outcomes, with a lifeexpectancy that is well below the national average in some neighborhoods. Philadelphia ranks last in the overall ranking of health outcomes of counties in the state of Pennsylvania ${ }^{4}$ and scores at the bottom of the chart in five categories: Health Behavior, Health Factors, Social and Economic Factors, Quality of Life and Length of Life. The average life expectancy for babies born to mothers in different neighborhoods in Philadelphia can vary by as much as 20 years ${ }^{5}$ and can be traced back to multiple factors that influence the health gap across neighborhoods. Access to health care, education and healthy food, walkability of neighborhoods, and the quality of the housing stock are some of the major drivers behind the health disparity.

\section{Lab for Urban and Social Innovation}

The Jefferson College of Architecture and the Built Environment (CABE) has a long-standing tradition of working with underserved communities in Philadelphia to improve the built environment by uniting community leaders, stakeholders, faculty and students. Design projects focus on improvements such as reduced dependence on vehicular transportation, walkable and bike-friendly communities, and redevelopment of mixed-use areas that promote walking. Based on its successful collaborative model, CABE founded the Lab for Urban and Social Innovation (LUSI) in 2016. Working collaboratively with neighborhoods and stakeholders, LUSI facilitates creating a vision of the built environment to strengthen the wellbeing of the community. Our process includes community workshops, design studios, design charrettes, funded research and consulting services. Using the National Charrette Institute ( $\mathrm{NCl}$ ) stakeholder approach, the collaborative process encourages participants to envision the unique and specific needs of their neighborhood and gives them a voice in the neighborhood's transformation. Through this process, LUSI helps to develop a shared vision and a broad network of stakeholders, connects communities with experts needed to implement the vision and helps find funding for the projects. As a result, communities will have greater access to green spaces and improved environment, increased social capital, improved local economy, better health equity and outcomes and reduction in crime. Drawing from its expert faculty and students in architecture, landscape architecture, interior design, geodesign, sustainable design, real estate development and allied disciplines, LUSI has been able to bring real change to Philadelphia's neighborhoods that are most in need. ${ }^{6}$

\section{Open Space Initiative: Cecil Street Community Park}

Through LUSI, the Landscape Architecture Program at Jefferson is proposing a network of block-by-block green spaces linking adjacent vacant lots to create green corridors of high quality outdoor spaces. With over 40,000 empty parcels, Philadelphia provides an unprecedented opportunity for the development of green spaces and community gardens. Living next to a green space or park boosts social well-being and mental health beyond just physical activity. The first pilot, transforming a vacant lot into a community-owned green space was launched two years ago as a collaboration with the community of Kingsessing in Philadelphia and the Jefferson Landscape Architecture Program in partnership with the John Heinz National Wildlife Refuge and Audubon Pennsylvania. Under the guidance of Professor Kim Douglas, landscape architecture students co-created a shared vision with the community and embarked on a design process that spanned the full semester. Over the summer, students and faculty worked with the community to determine the three sites for the intervention and to fully design the pocket park. Supported by the City of Philadelphia, Cecil Street Community Park is slated to be installed this year. A pre-and post-assessment developed in collaboration with the Jefferson Center for Urban Health and the Jefferson College of Population Health (JCPH), will measure the public health outcomes focusing on physical activity, community cohesion and connectedness and social well-being.

The next step will be to scale this intervention by building a robust process that involves local residents and entire neighborhoods in the planning and implementation process converting one block at a time into a linked system of green corridors. ${ }^{7}$

\section{"Rewilding" Cities}

Building on the one block-at-a-time Open Space Initiative, landscape architecture
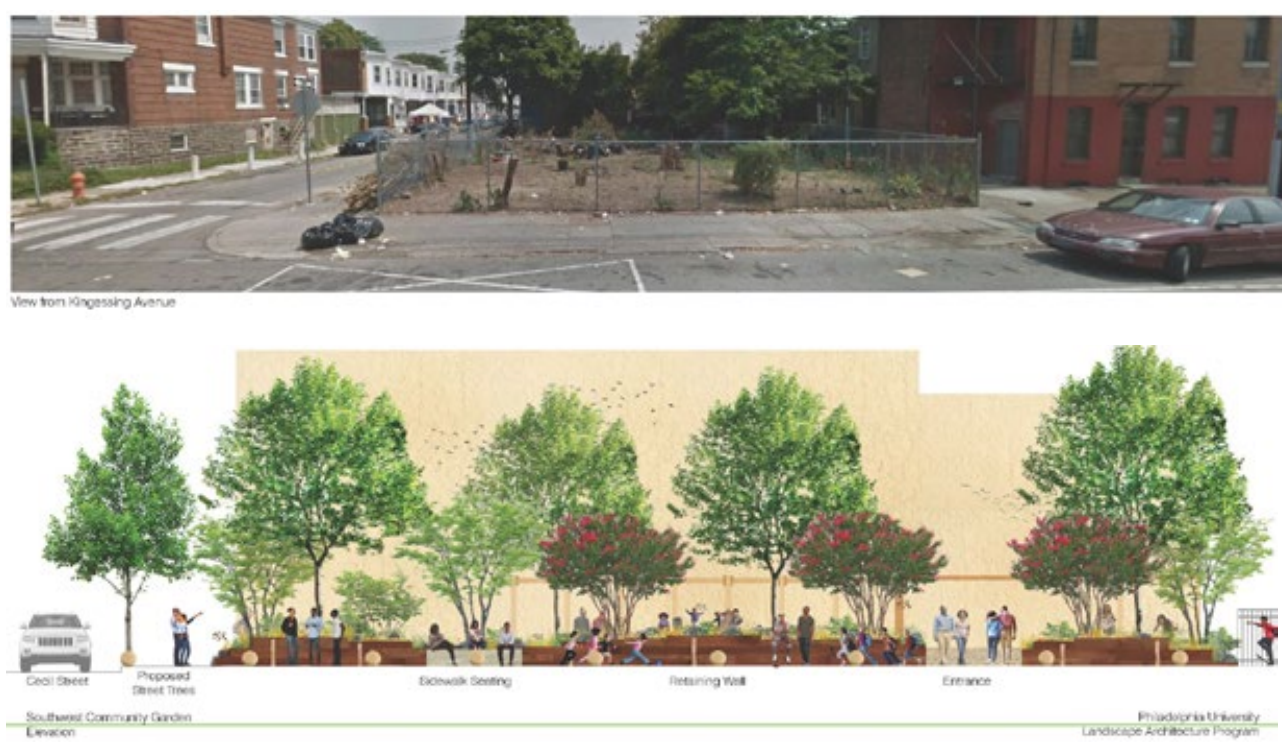

Cecil Street Community Park: Before and After 
students (under the guidance of Professor Kim Douglas, and in partnership with the John Heinz National Wildlife Refuge and Audubon Pennsylvania) designed, in a collaborative effort with the neighborhood of Eastwick in Southwest Philadelphia, a pollinator corridor eventually connecting the John Heinz National Wildlife Refuge, Fairmount Park and Cobbs Creek Park. This proposed contiguous green network will provide community members in underserved neighborhoods with access to green space within walking distance in a safe and engaging environment.

\section{Mill Creek Center for Arts and Innovation}

This collaborative project between the Jefferson Landscape Architecture, Sustainable Design and Geodesign programs focused on the former Mill Creek Arts and Cultural Center site in the Mill Creek area of West Philadelphia. It included the redevelopment of a small, mixed-use urban district that promotes the growth of art, technology, and design and reduced dependence on vehicular transportation. The clients, West Philadelphia Financial Services Institute and Progressive Community Development Corporation, were committed to working with the community to ensure their vision was realized. The development of the neighborhood around the Center focused on curtailed access between schools, churches and parks and the walkability and bikeability of the small neighborhood became essential parameters for the community. The design analysis built on guiding principles and initial concepts were developed using principles of sustainable design, landscape ecology, and transitoriented-development. The design team used advanced geospatial technology and 3D parametric modeling to demonstrate specific 'what-if' design scenarios to enable stakeholder and community members to engage in the decision process. During intensive 'rapid iteration' design sessions, all done live in realtime using 3D technology, community members could view in real time the designs and comment on what had been developed. A LUSI project, the design process included a broad network of stakeholders and community partners including Mill Creek Advisory Council (MCAC); the Business Association of West Parkside; LA21; Parkside Association; Cathedral Park Association; and Centennial Parkside Community Development Corporation. While this project was not implemented, it positively impacted the creation of social capital and community building in this neighborhood.

\section{Moving Forward}

LUSI helps change the narrative of underserved communities by identifying their strength and assets that can be used to increase positive outcomes and enable communities to address environmental, economic and social conditions of their neighborhoods that lead to better public health. When developers come knocking, neighborhoods can be ready with a plan in hand of what they want for their community and can negotiate accordingly.

In combatting health disparity in Philadelphia's neighborhoods, stakeholders have to partner in collaborative action to build healthier and more equitable communities. Jefferson recently formed the Philadelphia Collaborative for Health Equity to help establish partnerships across the city aimed at better serving Philadelphia communities. As educators in the architecture fields, we need to tie into the American Institute of Architects (AIA) Design and Health Initiative ${ }^{8}$ and educate our students to become advocates and stewards of a built environment that facilitates healthy behaviors. Working closely together with $\mathrm{JCPH}$, the College of Architecture and the Built Environment is committed to driving the change. Let's change the city one block at a time.

\author{
Barbara Klinkhammer, RA (DEU), Dipl.-Ing. \\ Dean and Professor \\ College of Architecture and the Built \\ Environment \\ Thomas Jefferson University \\ Barbara.Klinkhammerajefferson.edu
}

\section{REFERENCES}

1. Srinivasan S, O'Fallon LR, Dearry A. Creating Healthy Communities, Healthy Homes, Healthy People: Initiating a Research Agenda on the Built Environment and Public Health. Am J Public Health. 2003; 93 (9).

2. Frank LD, Engelke PO. Multiple Impacts of the Built Environment on Public Health: Walkable Places and the Exposure to Air Pollution. International Regional Science Review. 2005; 28 (2): 193-216.

3. Frank LD, Engelke PO. The Built Environment and Human Activity Patterns: Exploring the Impact of Urban Form on Public Health. J Planning Lit. 2001; 6 (2).

4. Philadelphia ranks \# 67 out of 67 counties in the overall ranking of health outcomes. Source: Robert Wood Johnson Foundation, County Health Rankings \& Roadmaps. http://www.countyhealthrankings.org/app/pennsylvania/2018/rankings/philadelphia/county/outcomes/overall/snapshot. Accessed July 6, 2018.

5. Robert Wood Johnson Foundation, Center on Society and Health. https://societyhealth.vcu.edu/work/the-projects/mapsphiladelphia.html. Accessed July 6, 2018.

6. The Jefferson Lab for Urban and Social Innovation (LUSI) unites communities, students, faculty and stakeholders in collective action through real-world design, construction and environmental projects. The Lab for Urban and Social Innovation's process uses a wide range of sustainable design strategies to make resilient, enriching and healthy solutions for communities. Supported by the broad expertise of its accomplished faculty, LUSI works alongside communities for research and design with a human-centered approach. http://www.eastfalls.jefferson.edu/ architectureandthebuiltenvironment/outreachProjects/index.html. Accessed July 6, 2018.

7. Douglas K, Harris D. Let's Promote Health and Green Space One Empty Lot at a Time. Philadelphia Inquirer, June 29, 2018. http://www.philly.com/philly/health/health-cents/lets-promote-health-and-green-space-one-empty-lot-at-a-time-20180629.html.

8. AIA Design and Health. https://www.aia.org/pages/3461-aias-design-and-health-initiative:31 


\section{Signs of Humanity: A Qualitative Exploration of the Panhandling Experience}

"Homeless, Anything Helps." It is nearly impossible to walk down Walnut Street without seeing someone in need. The signs are many and these situations are complicated. Poverty, food insecurity, mental health and addiction underlie the complex reality of need in our city. Many of us have trained our eyes, minds and hearts to look away, cross the street and move on. But, Willie Baronet, MFA realized that as a collection, these cardboard signs provide a glimpse into a phenomenon greater than each individual's plea for assistance. Baronet, in response to his own discomfort with people and the signs he passed by each day, began to stop, engage and ultimately purchase signs from people around the country nearly 20 years ago. Baronet carefully curates these signs and creates moving and powerful art exhibits to get people talking about poverty and homelessness. The work is provocative, controversial, and gripping.

Art, I admit, is out of my wheelhouse but when I heard Baronet on the radio some years ago I was affected and drawn to the opportunity to mingle art and research. Willie spoke about the informal conversations he had with "sign flyers" as he purchased the cardboard artifacts of poverty, deprivation, and addiction. I wondered if a formal analysis of the signs would yield deeper insight into the lived experience of those in need. I reached out to Willie and we soon became collaborators and friends. Willie was open and generous with time, energy, and his sign collection.

Our first collaboration led to a publication in the American Journal of Public Health ${ }^{1}$ and, as soon as that paper was done, we began to think about future ways to work together. In July of 2018 we did just that.

The Signs of Humanity (SOH) Project is a researcher-artist collaboration. This joint venture was designed to artistically and qualitatively explore the experience of the lives behind the signs with the goal of starting a conversation and reducing the dehumanization of this community. The work led to an installation made up solely of signs from Philadelphia. This is the first time Baronet's work focused solely on one

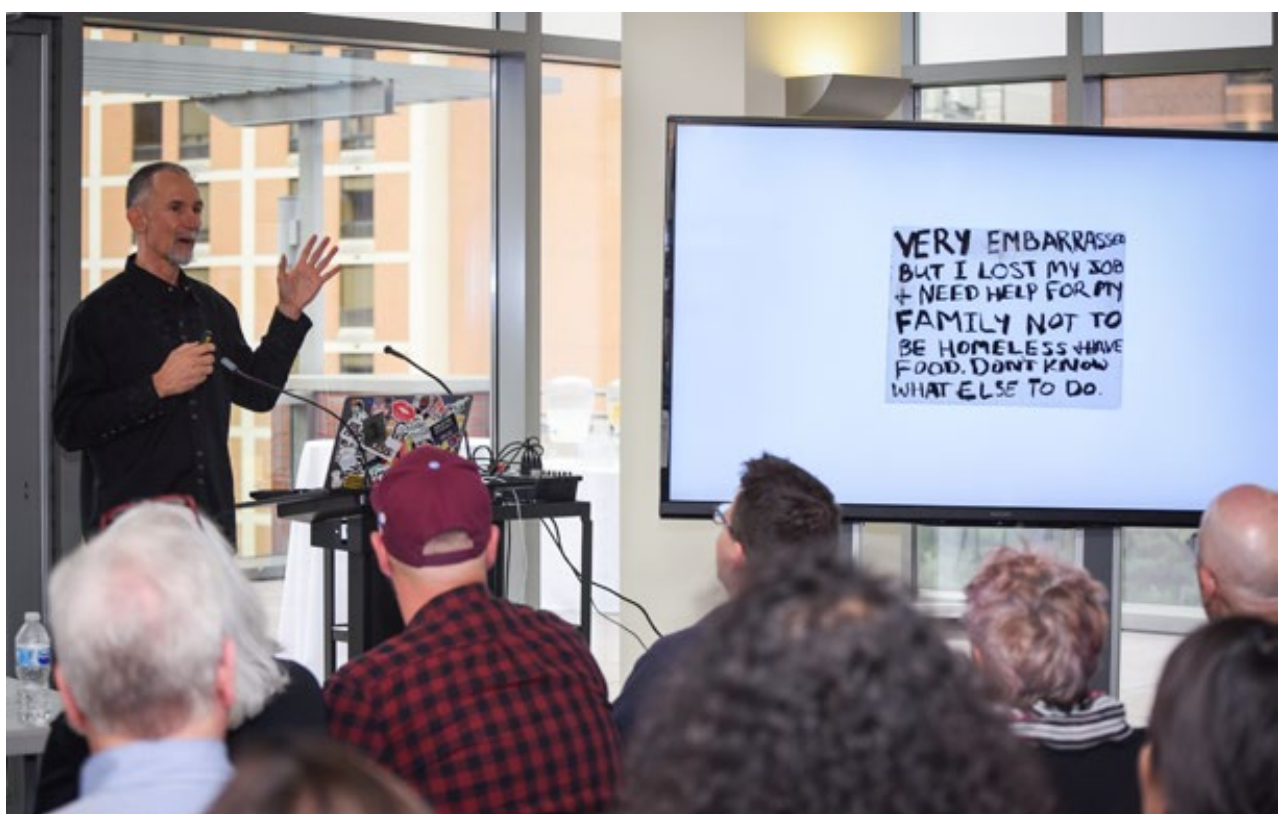

Artist Willie Baronet discusses Signs of Humanity project.

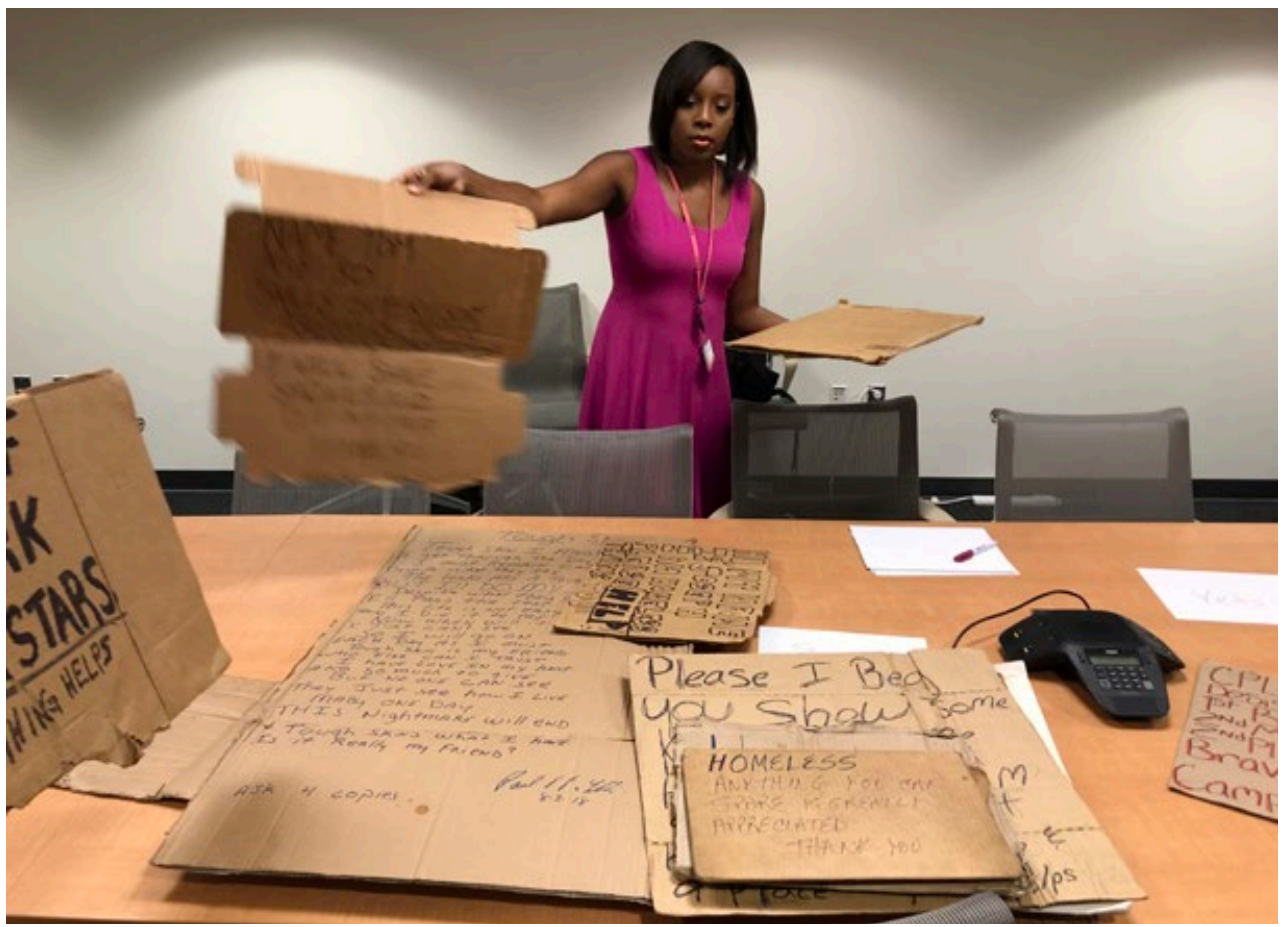

MPH Student Kaéla Edwards organizes for Signs of Humanity Exhibition.

\section{Key Study Personnel:}

Kaela Edwards, MPH candidate Alyssa Tate, MD candidate Nisha George, MPH (alum) Steven Buffer, MPH (alum) Nicole Holmes, MPH candidate Zach Fusfeld, MPH (alum) Emily Wei, MD candidate
Jenna Garret, MPH (alum) Katie Holland, MD candidate Josephine Hwang, MPH-MD candidate Katherine Brierley, MPH candidate Amy Cunningham, PhD, MPH, CPH Russ Mclntire, PhD MPH 
city. Second, a student generated display of preliminary research findings.

Working with an amazing group of dedicated MPH and SKMC students, Willie and I hit the streets in July. Willie purchased signs and the research team followed, inviting sign flyers to participate in the project and share their stories. We invited 42 people to participate and all but one agreed. Our research questions explored the lived experiences, including their interactions with passersby, their opinions about how money collected is used by their counterparts, their experiences with housing insecurity and their perception of how the opioid crisis has affected them. We collected demographic and geographic data and presented preliminary findings along side Willie's exhibit at Jefferson (hosted by Jefferson Humanities and Health) where nearly 100 signs hung from the ceiling for a week on our campus. Students, staff, faculty and visitors passing through the space could not really look away. They had to look, process, and engage. The exhibit included a screening of Baronet's documentary, Signs of Humanity and a panel discussion with Dave Malloy and Eddie Dunn, two Philadelphians, who shared their moving experiences of prior homelessness, addiction and recovery as well as reflections on their current work, family life, friendships and hope.

A comprehensive analysis of the project, in collaboration with JCPH Faculty, Drs. Amy Cunningham and Russ Mclntire, and several students, is underway. Preliminary findings underscore an overwhelming desire to be seen.

\author{
Rosemary Frasso, PhD, MSc, CPH \\ Associate Professor \\ Program Director, Public Health \\ Principal Investigator, \\ Signs of Humanity Project \\ Jefferson College of Population Health \\ Rosemary.Frasso@Jefferson.edu
}

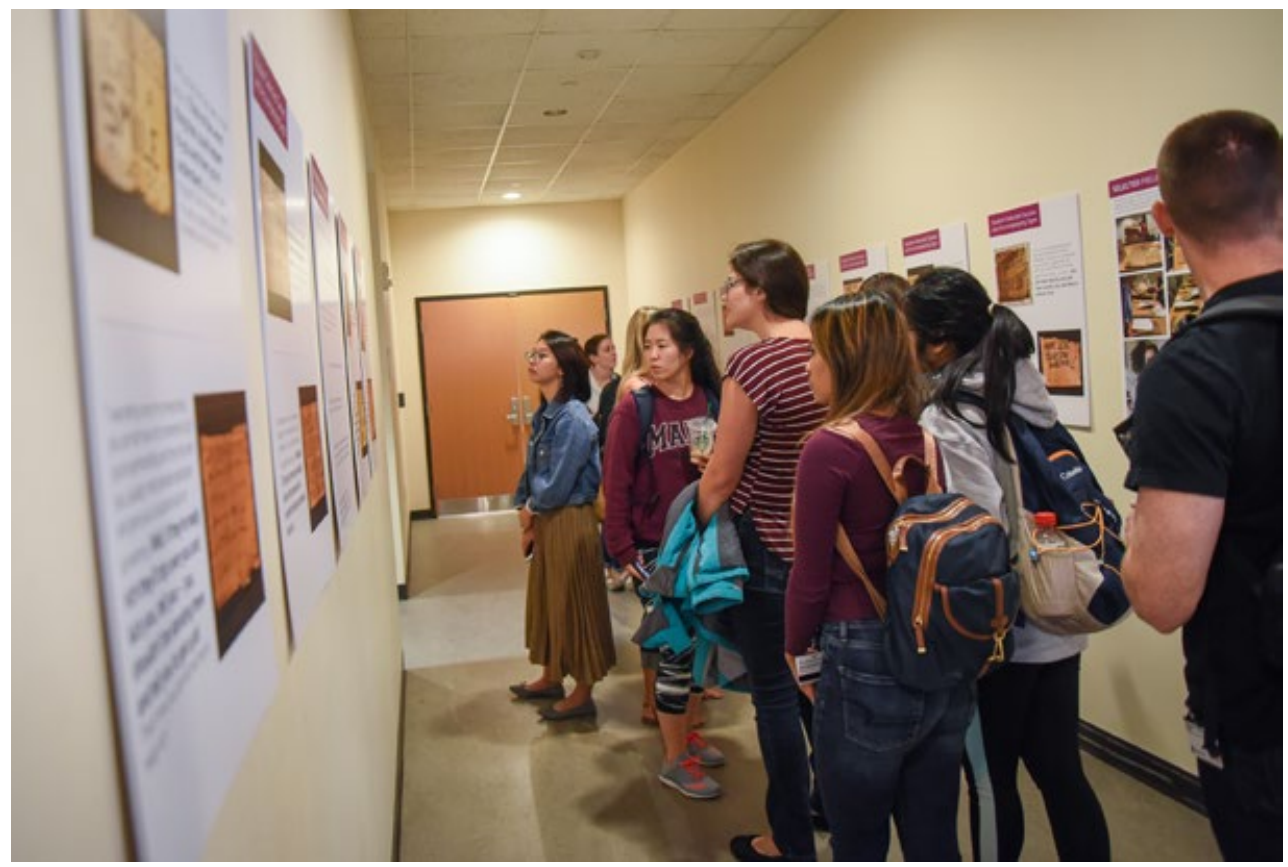

Signs of Humanity Exhibition

\section{Literature Cited}

1. City of Philadelphia Office of the Deputy Managing Director for Health and Human Services. 2016-2017 Panhandling Survey Report [Internet]. City of Philadelphia Office of the Deputy Managing Director for Health and Human Services; 2017 May [cited 2018 Jun 14]. Available from: http://www. philadelphiaofficeofhomelessservices.org/ wp-content/uploads/2017/03/may-2017panhandling-survey-executive-summary.pdf

2. Office of Homeless Services. All Households and Persons Point in Time Count PA-500 COC. 2018 May 1.

3. Philly mayor: Don't give cash to panhandlers | PhillyVoice [Internet]. [cited 2018 Jun 14]. Available from: http://www. phillyvoice.com/philly-officials-launchfundraiser-combat-increased-panhandling

4. Bose R, Hwang SW. Income and spending patterns among panhandlers. CMAJ. 2002 Sep 3:167(5):477-479.

5. Malterud K. Qualitative research: standards, challenges, and guidelines. Lancet. 2001 Aug 11;358(9280):483-488

6. Auriemma CL, Lyon SM, Strelec LE, Kent $S$, Barg FK, Halpern SD. Defining the medical intensive care unit in the words of patients and their family members: A freelisting analysis. Am J Crit Care. 2015 Jul;24(4):e47-55.
7. Systematic Data Collection - SAGE Research Methods [Internet]. [cited 2018 Jun 18]. Available from: http://methods.sagepub. com/book/systematic-data-collection

\section{Jefferson Signs of Humanity Press}

1. Jefferson Today University News. The concept of home explored in Jefferson's "Signs of Humanity" Exhibit. September 27, 2018 http://wordpress.philau.edu/today/2018/ 09/27/the-concept-of-home-explored-injeffersons-signs-of-humanity-exhibit/.

2. Signs of Humanity 2018 Thomas Jefferson University Student Reflections. https://www.youtube.com/ watch?v=u4hW-OBEVsc\&feature =youtu.be

3. Udo J. Homeless people's signs permeate art exhibition to raise their awareness about their plight. KYW News Radio 1060. September 20, 2018 https://kywnewsradio. radio.com/articles/homeless-peoplessigns-permeate-art-exhibition-displaythomas-jefferson-university-raise

4. Wolters C. Signs of the homeless go on display for art and research. Philadelphia Inquirer. September 13, 2018. http:// www2.philly.com/philly/entertainment/ arts/homeless-philadelphia-signs-ofhumanity-willie-baronet-20180913.htm

\section{REFERENCES}

1. Golinkoff A, Hall M, Baronet W, Cannuscio C, Frasso R.

Cardboard commentary: a qualitative analysis of the signs from America's streets. AJPH.2017;06(11)1977-78.

https://ajph.aphapublications.org/doi/10.2105/AJPH.2016.303290. Accessed October 6, 2018. 


\section{Public Health on the Front-Line: Bridging the Gaps}

$\mathrm{MPH}$ students at the Jefferson College of Population Health (JCPH) have the opportunity to supplement classroom learning with activities and programs that provide deeper insight into communities through tangible field experiences. One such program is Bridging the Gaps (BTG), a community health internship that offers students front-line experiences and skills for working with vulnerable populations. BTG is a consortium comprised of universities in the region and other affiliate programs. The program makes a strong effort to promote interdisciplinary collaboration by recruiting interns who are studying public health, medicine, nursing, social work, occupational therapy, and other health and social service professions.

This past summer two JCPH MPH students, Ellen McQuaid and Talia Charidah, participated in BTG. The following article highlights their experiences.

\section{ELLEN'S EXPERIENCE}

This summer I had the pleasure of participating in the Bridging the Gaps (BTG) community health internship program where I was placed at Mercy Hospice, a nonprofit organization under the Housing and Homeless Services of Catholic Social Services of the Archdiocese of Philadelphia. Mercy Hospice is a residential home for women and their children as they go through off-site, outpatient treatment programs for addiction and mental health conditions. Mercy offers on-site case management, parental education, and emotional support for the women and their children. Mercy has 48 beds for the women and children who are referred to them through the city's Office of Addiction Services, and there are typically 30 individuals residing at Mercy, split between two case managers.

Throughout the 7-week internship, I was paired with a Masters in Social Service student from Bryn Mawr College. Some of our goals throughout the program were to provide emotional support for the women; assist in employment skills; help women to maintain physical health; assist in the move from transitional to permanent supportive housing; and foster a more supportive environment for the mothers in the program. We achieved these goals through various activities, such as assisting the residents in making doctor, dental, and psychiatry appointments; providing resume guidance and assistance in applying for jobs, and creating a resource book of free and low-cost family fun activities around the city for the residents with children.

We were able to work at Mercy Hospice from Monday through Friday, except for every Wednesday when open learning seminars were scheduled for all BTG interns. These sessions helped us better understand the populations we were working with, along with helping us gain useful tools for the field such as mandated reporting protocol, resource sharing for our sites.

This internship was incredibly rewarding not only through a public health lens, but it gave me a greater appreciation for the dedicated people working in this emotionally taxing field. I feel very fortunate that I was able to witness, on a personal level, the havoc an opioid addiction can have on one's life. Not only did I observe the tremendous pain that has come from addition and homelessness, but also I saw how people can heal in a supportive environment paired with treatment. The biggest takeaway from this experience for me was that epidemics, such as this opioid crisis, need an interdisciplinary health approach to be combated effectively. I am very appreciative to have been able to have my BTG experience at Mercy. The staff was so incredibly welcoming and supportive; they provided me with the type of learning experience that I will carry with me throughout my public health career.

\section{Ellen McQuaid \\ MPH Student '19 \\ Jefferson College of Population Health Ellen.McQuaidaJefferson.edu}

\section{TALIA'S EXPERIENCES}

I was first exposed to the BTG program the year before I began my MPH at Jefferson. I was working at a refugee resettlement agency in Philadelphia, Nationalities Service Center, on the health team, where two BTG interns happened to be placed. They informed me of the program and the opportunity to work in a community health setting and engage with students from other universities in multiple disciplines. Once accepted into the BTG program I was eager to be placed at a community partner in the Philadelphia area.
My community partner placement was at Mazzoni Center, an LGBTQ-focused center that provides comprehensive health and wellness services from primary care to counseling and recovery services. Mazzoni Center is the only healthcare provider in the Philadelphia region specifically targeting the health care needs of the lesbian, gay, bisexual and transgender communities. Mazzoni Center combines HIV/AIDSrelated services with a broad continuum of healthcare and supportive services, including outreach, prevention, education, direct medical care, case management, psychosocial services, legal services, a food bank, trans care and support groups. I had the privilege of working in the health center under my community preceptor, Andrew Gudzalek, data analyst for Mazzoni. I was placed in the health center with Jessie, a medical student from Jefferson, and we worked together on different data projects and assignments over the course of the BTG program.

This past summer, as interns, we engaged with various departments at Mazzoni Center. One of our main projects was to work with Andrew to assist in running and reviewing data reports to track client health status and progress. Data was mostly

Continued on page 10

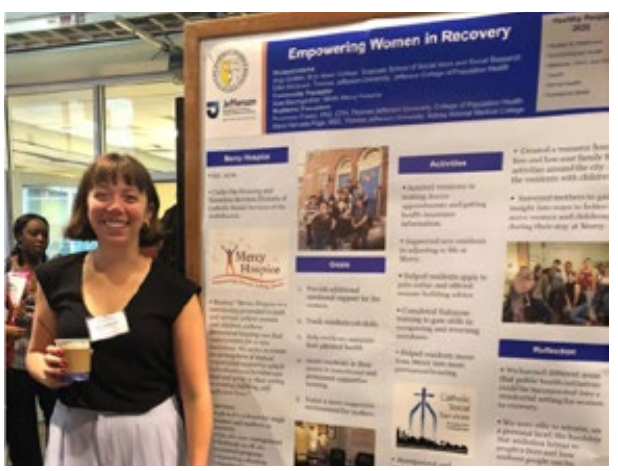

MPH Student Ellen McQuaid

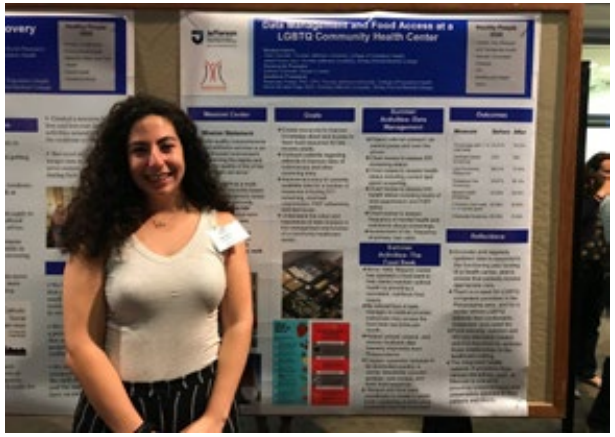

MPH Student Talia Charidah 
social services, case management, behavioral health services etc., Mazzoni Center is able to provide comprehensive care to a population that is often marginalized within the healthcare system. Mazzoni promotes an LGBTQ-focused environment, and the provision of LGBTQ-competent care, which is something I believe should be incorporated into all healthcare providers and public health professionals' practice. Just like any other group of patients, LGBTQ-identified patients have a right to feel respected, safe, and cared for, especially in the healthcare space. Because of this, I will use the knowledge I have obtained from observing providers and examining the way that Mazzoni Center operates, and advocate for LGBTQcompetent care in all healthcare spaces. This can be in the form of making sure that the agency I choose to employ myself with uses trans competent forms and making sure that the EMR system at this agency recognizes patients' preferred pronouns and names.

Overall, my experience with BTG allowed me to incorporate my previous public health knowledge while also learning more about a population that I have not been exposed to within my public health professional life. Because the program is interdisciplinary, I was able to learn from my fellow students about the populations they were working with, as well as collaborate with them on ways to improve the current healthcare system and how we, as future health professionals, can prioritize the health and wellbeing of our patients and clients while actively trying to change the system that marginalizes the groups we worked with. From this experience I will take away a greater appreciation for collaboration and how important it is for each provider, from public health workers to clinicians, to play an active role in the treatment and service provided to patients and clients.

Talia Charidah

MPH Student '19

Jefferson College of Population Health

Talia.Charidah@Jefferson.edu to observe the ways in which an integrated health center operates. By incorporating

\section{Service Learning for Public Health Education: A Window Into the World Next Door}

The Jefferson College of Population Health (JCPH) Master of Public Health (MPH) program requires all students to complete a clerkship with a public health organization in order to graduate. The clerkship is designed to allow students to apply classroom knowledge in a practice setting through service learning. In the past, organizing and completing the clerkship was a particular challenge for MPH students on the accelerated (also known as LEAP) pathway.

This past year, JCPH collaborated with Philadelphia FIGHT to create an innovative semi-structured clerkship experience for its students. Philadelphia FIGHT (a name chosen to represent resiliency and hope in the face of hardship) is a renowned network of Philadelphia-based Community Health Centers that provides a wide variety of services for people who are HIV positive or at high risk of HIV., ${ }^{1,2}$ FIGHT engages in mental, oral, and physical health care, outreach, community justice, research, education, and much more. ${ }^{2}$ Their clients face a host of challenges and for many, FIGHT is the only place they are treated with respect.

\section{Figure 1: MPH Student Reactions to Letters from Incarcerated Individuals}

Having physical, handwritten letters humanizes the experience and the people. It provides a connection to the writer and makes me feel more in touch with what they're going through.

$$
\text { - Nisha George }
$$

Reading these prisoners' stories highlighted the shortage of information available in prison. They need information about so many things because they are

very cut off and alienated. This isolation is extremely clear in their letters. - Zachary Fusfeld

One letter was from an individual who was concerned about their family at home. They were asking for somebody to go visit their elderly mother because they were not able to. It was heartbreaking.

$$
\text { - Paul Sebastian }
$$

We were two of $34 \mathrm{MPH}$ students collaborating with FIGHT Volunteer Manager Nikki Bromberg, MSW to achieve a number of organization goals, including: generating accessible health education material for a newsletter sent to inmates in prisons and jails across the US; conducting quality improvement surveys with FIGHT clients; engaging in community outreach for a $\operatorname{Narcan}^{\circledR}$ (naloxone) training program; developing educational workshops for
FIGHT's HIV Prevention and Outreach Summit; and completing other public health activities individualized to students' personal interests.

Our duties within the organization have exposed us to the stark realities of income inequality that are so characteristic of Philadelphia and shown us their direct influences on health and well-being. FIGHT's health centers treat people who 
are frequently marginalized (eg, those experiencing homelessness, substance use disorder, and severe mental illness) in our urban community who often have serious health problems and seemingly nowhere to turn for help.

Particularly meaningful experiences have come from conducting quality improvement surveys to help FIGHT achieve their mission of providing culturally competent comprehensive care. We asked clients a comprehensive battery of questions including whether their provider has talked to them about harm-reduction methods like Narcan ${ }^{\circledR}$ or pre-exposure prophylaxis (PrEP). PrEP is a daily pill that can decrease risk of HIV transmission by $90 \%$ and can be a gamechanger for individuals looking to keep themselves or their partners safe. ${ }^{3,4} \mathrm{~A}$ great number of clients we spoke to had never heard of PrEP through their providers, and after learning a bit about PrEP, many were very interested and mentioned they would ask about it at their next visit. One client expressed his amazement that he had never heard of PrEP before, and explained with astonishment that because of it, he might be able to have another child.

Another major duty within the clerkship program was to write articles and subscriber correspondence for FIGHT's Institute for Community Justice Prison Health News (PHN) publication. This newsletter is provided free of charge to a national readership of incarcerated individuals, with the goal of providing health education information to people in prison and to give subscribers a voice. Every volume of PHN provides a correspondence address for prisoners to contact in order to obtain health education information to guide personal health decision making. MPH program participants spend many hours each week reading and responding to subscribers' letters to prepare people in prison for reentry into society, educate them about prison medical care processes like medical grievances and prisoner medical rights, and answering questions related to personal health issues with valid information from reputable sources. Many letters are benign, but an astonishing proportion have positioned us to reflect on the state of criminal justice in America in 2018; from crippling mental health problems to jaw-dropping abuse and injustices within the prison system, we have been presented with the challenge of deciding how best to help these individuals with our stockpile of medical, legal, and social resource information materials. We have worked to develop the art of replying to letters formally while providing a touch of compassion and caring to those who reveal, through their writing, deeply personal stories, hoping that we might provide them with information that they cannot access on their own while behind bars. Many students in our cohort report reading these letters to be an emotionally difficult but life-changing experience (Figure 1).

The vibrant collaborative relationships developed with FIGHT staff provided $\mathrm{MPH}$ candidates with an opportunity to experience firsthand the importance of public health practice while contributing to a highly impactful non-profit organization. Nikki Bromberg's dedicated attentiveness to diverse individual student interests and talents has opened doors, forged professional relationships, and deepened our understanding of competent, informed public health practice. This collaboration has been well-received both by FIGHT staff and by MPH students and we hope to see it continue to thrive and grow with successive student cohorts.

\section{John "Jack" King, MPH \\ Katrina Bazemore, MPH \\ John and Katrina are recent graduates of the JCPH MPH program.}

\section{REFERENCES}

1. Philadelphia FIGHT. Community Health Centers Archives. Philadelphia FIGHT 2018. https://fight.org/programs-services/community-health-centers/ Accessed June 12, 2018.

2. Philadelphia FIGHT 2018. https://fight.org/. Accessed June 12, 2018.

3. CDC. PrEP. HIV Basics 2018. https://www.cdc.gov/hiv/basics/prep.html. Accessed June 12, 2018.

4. Philadelphia FIGHT. PrEP. Philadelphia FIGHT 2018. https://fight.org/programs/prep/. Accessed June 12, 2018.

\section{Nexus Maximus 2018: Multidisciplinary learning linking Community Health and Innovation}

Nexus Maximus is a conference that gathers students from all over the globe for 4 days of "sprint-style" collaborative problemsolving. Students are put on multidisciplinary teams of 5-7 to create solutions to problems within a given theme. This year's theme was "Improving Lives through Healthy Communities," and each team was assigned a neighborhood within Philadelphia. Given my interests in creativity, design, and entrepreneurship in healthcare, Nexus Maximus sparked my interest. I thought it would be an excellent opportunity to develop my entrepreneurial problem solving skills while meeting like-minded peers and working on important problems within the community health space.

My team included students from Jefferson's Interior Design program, Pace University, HS Owl in Germany and Yansei University in South Korea. We were assigned the Center City area of Philadelphia which is the primary commercial district in the city. There is a lot of pedestrian traffic in Center City, and people in need migrate to this area in hopes of securing support. Many of the people we see on the street are struggling with housing insecurity, health issues, including addiction and of course poverty. I suggested we focus on homelessness. I had just attended Signs of Humanity event sponsored by SKMC and $\mathrm{JCPH}$. At the event, artist Willie Baronet and $\mathrm{MPH}$ program director Dr. Rosemary Frasso

Continued on page 12 
different to the table. Reflecting on the problem with students from different disciplines and countries added depth to the conversation about barriers community members face to supporting the homeless. My teammates from Germany and South Korea spoke about the culture around asking for help on the streets in their countries. In addition, each student on my team came from a different discipline. Combined, we had backgrounds in public health, design, finance, and information technology. This allowed us to think about the problem from multiple angles. We brainstormed several ideas and were able to share some of them with a wider audience. The problem of poverty is complex.

When we weren't working on our project, we attended workshops on Innovation, Sustainability, GIS mapping tools, and Consumer Centricity and developed relationships with visiting faculty and students. The conference provided a well-

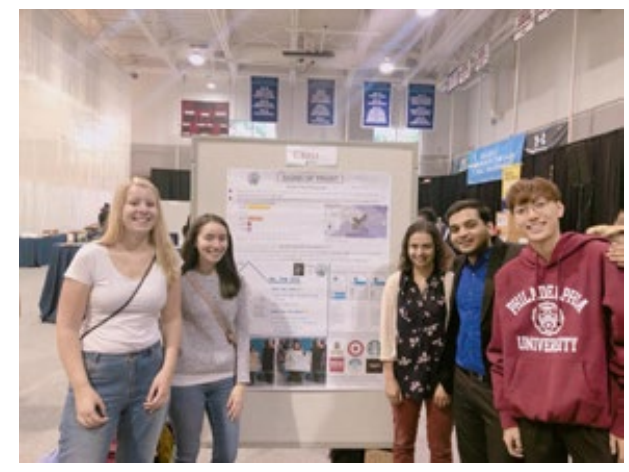

Sylvie Abookire (3rd from right) and her team at Nexus Maximus.

rounded and exciting glimpse into the world of population health innovation.

\section{Sylvie Abookire}

MPH Student

Jefferson College of Population Health

Sylvie.Abookire@Jefferson.edu

\section{The Muller Institute for Senior Health: Innovative Programs to Address Aging}

\begin{abstract}
"Older adults have unique needs. To prevent harm to older adults, improve health outcomes, and lower overall costs, health care systems must adopt evidencebased models and practices that deliver better care to our rapidly aging population across all settings, including the home and community" (John A Hartford Foundation, Age Friendly Health Systems care).
\end{abstract}

Abington Hospital Jefferson Health serves a community with one of the largest older adult populations in Pennsylvania, many of whom are vulnerable and need care and advocates across the health system. It is the mission of the Muller Institute for Senior Health to address the concerns unique to this group and to work with our healthcare colleagues to keep older adults safe and cared for in the hospital, and leading comfortable lives in the community. We do this through a variety of programs and services including the Hospital Elder Life Program (HELP), the Geriatric Assessment Center (GAC), the Memory Fitness Center (MFC), ElderMed, Caregiver's Support Groups, APPRISE health insurance counseling, Operation Reassurance, a Caregiver's Resource Room, dementia and caregiver related counseling, and the Stop Abuse in Later Life (SAILL) program.

The Muller Institute for Senior Health was created in 1999 with a very generous grant from C. John Muller, who wanted an ongoing sustainable program to represent his legacy at Abington Hospital. Two programs already in existence were ElderMed, a free wellness membership program for seniors providing seminars, social events, and insurance counseling with over 11,000 members; and the Geriatric Assessment Center, a comprehensive evaluation service staffed by a geriatrician or geriatric nurse practitioner and a geriatric social worker. From these two very successful programs, and with the grant from Mr. Muller, we were able to add programs and services when we identified a patient or community need.

The first new program we implemented was the Hospital Elder Life Program (HELP). We were the $12^{\text {th }}$ hospital, of what has become an international program, to sign onto this evidence-based, volunteer-driven inpatient initiative. HELP has been proven to reduce delirium in hospitalized older adults and is associated with reduced length of stay and rehospitalization. We have become a Center of Excellence and visit over 5,000 patients per year. We manage close to 100 volunteers a year, including many student interns, which make us an intergenerational training program as well. Many of our volunteers are students applying to medical school or schools of Allied Health; they welcome the hands-on experience they receive working with the older adult patients.

Recognizing the importance of caregivers, we opened a Caregiver's Resource Room and offer two caregiver support groups monthly. In conjunction with the Pennsylvania Department of Aging's APPRISE program, we have a counselor on site to help with myriad health insurance questions. We inherited the Operation Reassurance program from the County's Aging and Adult Services, where older, community-dwelling adults call in daily so that our operators know they are safe and sound. The SAILL program is a continuation of the Hospital's strong commitment to address domestic violence in our community, focusing on all types of abuse and neglect that older adults may experience, both in the home and in long-term care facilities. 
The Memory Fitness Center (MFC) and Geriatric Counseling service are our two newest programs. The MFC operates in two outpatient locations, up to five days per week. From 11:00am to 3:00pm, we provide a program designed to help sharpen the memory skills of adults who are showing signs of memory loss or have recently been diagnosed with dementia or mild cognitive impairment. The program includes physical exercise, brain games, socialization and lunch. It gives the participants a safe and comfortable space where getting the right answer or remembering all the facts are secondary to interacting with others outside their homes and families. Because it provides respite for caregivers, we believe it strengthens family relationships and delays the need for external placement. The Geriatric Counseling service is staffed by licensed clinical social workers responding to client stress related to memory loss as well as caregiving responsibilities. Referrals come from the GAC, neurology and geropsychiatry.

The recent changes in reimbursement and the emphasis on patient-centered care compel all healthcare entities to better address the needs of the patients and the communities where they reside. We need to constantly improve our professional communication and, with that, improve the quality of the transitions of care by patients across the healthcare continuum. At the Muller Institute, we have built strong relationships with our long-term care providers and are working closely with our own home care department. Together with the Palliative Care department we offer an annual advance care planning presentation for the community. We have been visited by delegations from New Jersey, Salt Lake City, Singapore, and North Carolina who are interested in seeing our programs. We have supervised hospitals that want to strengthen their own programs and have presented at national and international conferences (including Hospital Elder Life Program and Nurses Improving Care for Healthsystem Elders).

Largely because of Mr. Muller's very generous gift, we have been able to sustain programs that many hospitals have had to abandon, while at the same time adding new ones. We see our role as advocates for older adults, both within the hospital and in the community we serve. Health care has become a "hightech, low -ouch" industry; many older adults benefit from just the opposite, a "low-tech, high-touch" approach. We will be working closely with our Jefferson colleagues in the John A. Hartford Foundation Age-Friendly Health System Initiative which, in conjunction with the Institute for Healthcare Improvement (IHI) has a goal of developing an Age-Friendly Health System model and spreading the model to 20 percent of US hospitals and health systems by 2020. Our goal at the Muller Institute, as it has been for almost twenty years, is to provide the very best programs and services to older adults in our community and now, with our merger with Jefferson Health, throughout the Enterprise.

Sarah L. Maus, LCSW, ACSW

Manager of Geriatrics

Muller Institute for Senior Health

Abington Hospital - Jefferson Health

Sarah.Maus@Jefferson.edu

\section{SAVE THE DATE!}

\section{March 18-20, 2019 \\ ACADEMIC PARTNER:}

Loews Philadelphia Hotel

\section{Philadelphia}

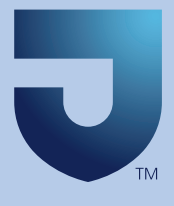

Jefferson

Philadelphia University + Thomas Jefferson University
College of Population Health

\section{Nineteenth Population Health Colloquium}

\section{www.PopulationHealthColloquium.com}

\section{HIGHLIGHTS:}

- Announcement of the winner of the 2019 Hearst Health Prize for Excellence in Population Health

- PHA Forum 2019

- Special Tuesday Night dinner focused on the future of medicine — how cutting-edge medical breakthroughs are transforming care

A Hybrid Conference,

Internet Event \&

Training Program

- Presentations from top industry leaders who are revolutionizing healthcare

- Networking opportunities, including an Opening Night Reception featuring Hearst Health Prize finalists

- Exhibit hall featuring new and exciting solutions, products and services

\section{The Leading Forum on Innovations in Population Health}

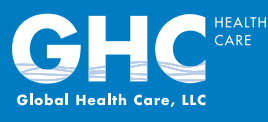




\section{Navvis and TJU Establish Professorship in Population Health}

Navvis and JCPH have established the country's first private sector-supported academic chair in population health The Navvis Professorship of Population Health. The Professorship will focus on identifying methods and best practices to create systemic, effective and scalable improvements in health.

Funded by Navvis, a population health company headquartered in St. Louis, Missouri, an endowment of $\$ 2$ million will support the work of a dedicated faculty member at JCPH. The academic research will be national in scope, and explore critical population health topics such as: social determinants of health; physician and patient engagement, including shared decision making; person-centric care: provider network alignment; and payment transformation strategies, with the goal of improving intervention effectiveness in realworld applications.

"Establishing an endowed professorship devoted to the health and wellbeing

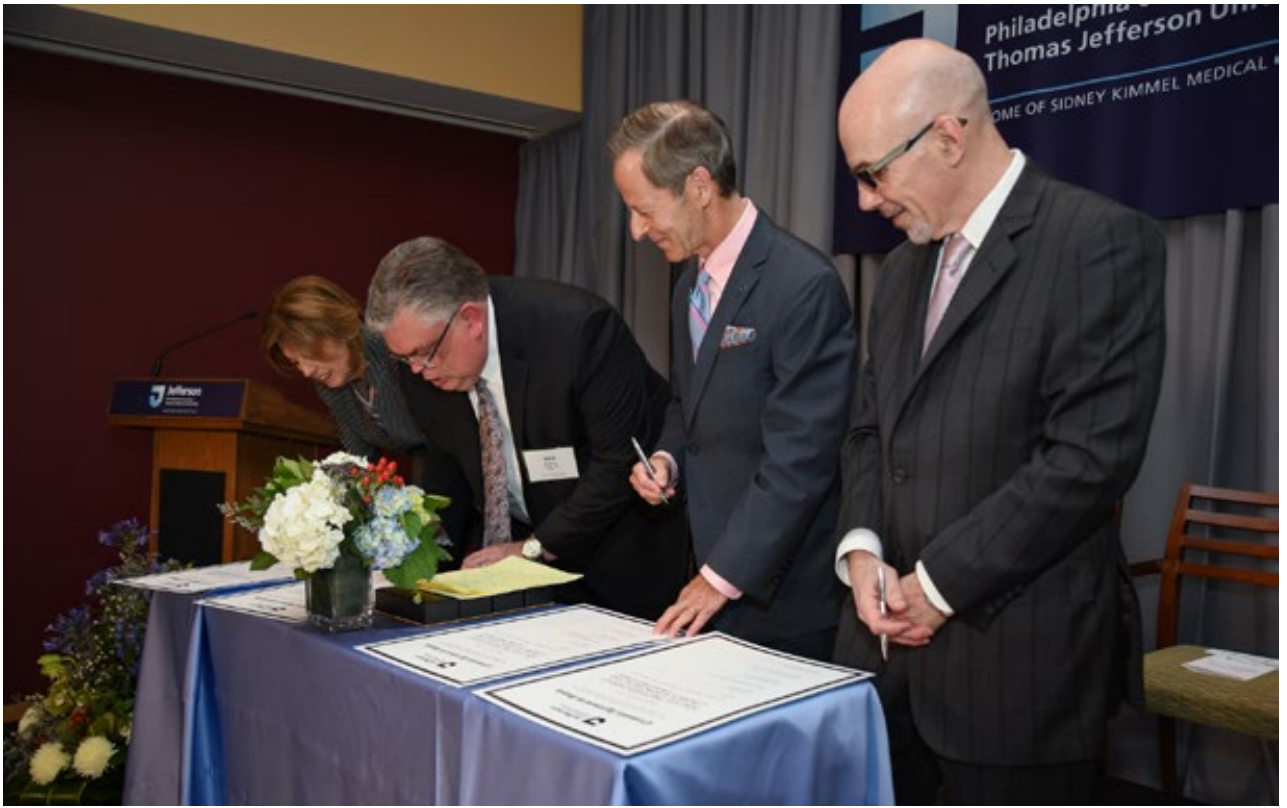

Official signing between Jefferson and NAVVIS

of whole communities is an invaluable investment in humanity," explained Dr. Nash. "We are grateful for Navvis' foresight and generosity, and look forward to working together to make a difference."

\section{UPCOMING POPULATION HEALTH FORUMS}

November 14, 2018

Diagnostic Error: A Patient Safety Initiative

Rebecca Jones, MBA, BSN, RN, CPHRM, CPPS

Director of Innovation and Strategic Partnerships

Director, Center for Excellence for Improving Diagnosis

Pennsylvania Patient Safety Authority

\section{Timothy J. Mosher, MD}

Kenneth L. Miller Chair of Radiology

Distinguished Professor of Radiology and Orthopaedics

Penn State Hershey Medical Center

Penn State College of Medicine

Physician Advisor, Center for Excellence for Improving Diagnosis,

Pennsylvania Patient Safety Authority

\section{December 5, 2018 \\ Approaching Value-Based Contracts at an Academic Medical Center}

\author{
Harry S. Saag, MD, FACP \\ Medical Director, Network Integration and Ambulatory Quality \\ Assistant Professor, Department of Medicine \\ NYU Langone Health \\ NYU School of Medicine
}

Details and Registration:

Jefferson.edu/PopHealthForum

Forums take place from 8:30am - 9:30am and are free of charge. Forums are designed for Jefferson students, faculty and staff; health care professionals, administrators, public policy analysts, advocates, and community health leaders.

For more information visit: Jefferson.edu/PopHealthForum

\section{Missed a Population Health Forum?}

You can listen to Forum presentations and view slides on Jefferson Digital Commons (JDC): https://jdc.jefferson.edu/hpforum/ 


\section{Implementing Jefferson Health's Electronic Clinical Quality Metric Reporting}

Jefferson Health is a large health enterprise in the Philadelphia Metropolitan area, composed of 14 hospitals, that employs hundreds of primary care clinicians in over 100 primary care practices. In 2016, Jefferson embarked on an exciting journey to transform its outpatient practices by taking part in the Comprehensive Primary Care Plus (CPC + ) program. CPC+ is a 5-year grant sponsored by the Centers for Medicare \& Medicaid Innovation (CMMI) to test the hypothesis that outpatient quality outcomes could be improved with an improvement in infrastructure and payment reform in primary care practices. Nationwide, approximately 3,000 primary care practices $(13,000$ clinicians) in 14 regions were chosen to take part in CPC+ in the fall of 2016. Sixty-one owned Jefferson Health primary care practices and 3 affiliated sites were chosen to participate as part of this group.

While the program is sponsored by the Centers for Medicare and Medicaid Services (CMS), the structural reforms provided have to be utilized to improve the care provided for all patients in a practice, including those who are commercially insured. The domains of clinical quality, healthcare costs, and patient experience are measured to assess improvements. The enterprise used CPC+ as an opportunity to standardize processes and workflows across a large integrated network. Since improving quality outcomes was an important tenet of the program, a quality committee was formed to oversee clinical quality initiatives and to fulfill one of the mandates of the CPC+ program (reporting these quality metrics to CMS).

Electronic clinical quality metrics (eCQMs) are formulated to utilize structured data from the outpatient electronic medical record (EMR) to tabulate performance on quality metrics. These metrics use evidenced-based criteria established by national organizations (such as the National Quality Forum (NQF) and the National Committee on Quality Assurance (NCQA).

The eCQMs also follow the framework established by previous Medicare quality programs, with all of the measures defined by one of the CMS Quality Strategy
Domains that have been established and refined over the past few years:

- Effective Clinical Care

- Communication and Care Coordination

- Patient and Caregiver Engagement

- Community/Population Health

- Patient Safety

- Affordable Care

There were two related but distinct areas that required the attention of the enterprise in order for the program to succeed. First, the enterprise needed to ensure that the performance on the eCQMS reflected the actual clinical quality being delivered in the enterprise's primary care practices. One of the large challenges was that each of the campuses that make up Jefferson Health has a different electronic medical record (EMR) with similar but distinct capabilities. This meant that the Informatics Systems and Technology (IS\&T) departments of each of the major campuses had to work with separate vendors to ensure that the data was being collected in line with the specifications set forth by the respective EMRs. This work had to be accomplished in very short order, given the compressed timeline between the grant award and the deadline to start collecting data. The IS\&T departments had to be educated about appropriate documenting and data collection for optimal reporting. Additionally, clinicians, medical assistants, and office mangers required education on recording clinical quality metrics in each of the predetermined structured fields in the EMRs.

The next step was to make sure that the information that had been collected could be successfully submitted to CMS. This meant that the respective population health and IS\&T departments on each campus had to make sure that the structured data fields in the EMRs were linked appropriately to capture the quality metrics. In 2017, CMS required that all participating CPC+ practice have a mechanism for collecting and reporting on pre-approved quality metrics from a menu of 14 . While CMS only required reporting on 9 of the 14 total quality metrics, they encouraged the CPC+ practices to develop strategies for monitor and implementing improvement strategies on the entire menu of quality metrics. This process enlisted multiple stakeholders and it took several months to get to the point where the metric collection and reporting was ready to be implemented. This occurred about halfway through the first year of the program with results ready to be shared with Jefferson Health administration and office staffs.

Each campus was able to utilize an eCQM dashboard that listed the numerators, denominators and percentage completion for all of the quality metrics with year-todate performance. The dashboards were accessible by all clinicians and practices, with the ability to utilize the data to develop clinical quality improvement projects based on Plan-Do-Study-Act (PDSA) cycles. The vast majority of the practices were able to dramatically improve their quality metric performance with most able to reach or exceed eCQM benchmarks set by CMS. In addition, the CPC+ quality committee created an enterprise-wide scorecard that included the results for multiple metrics that the committee decided would be common focus for 2017 (Table 1). This information was socialized to top-level administrators working in the areas of

\section{Table 1: Ambulatory Quality Scorecard Metrics}

\footnotetext{
- Diabetes Control $\mathrm{HbA} 1 \mathrm{c}<=9 \%$

- Diabetes Retinal Screening

- Colorectal Cancer Screening

- Breast Cancer Screening

- Cervical Cancer Screening

- Tobacco Use Screening and Cessation

- Controlling High Blood Pressure

- Falls Screening
}

Continued on page 16 
Calendar year 2018 brought a few changes to the eCQMs including the addition and removal of previously reported quality metrics. The Jefferson Health CPC+ Quality Committee once again agreed upon multiple metric that would be a common focus for each of the campuses. With the changes in the program, the IS \& T departments and vendors on each campus have had to work through the configuration of new metrics and reconfiguration of metrics that have changes to the specifications. The 2018 eCQM dashboards have been activated on all the campuses with performance socialized to every CPC+ practice. Jefferson Health is confident that the quality improvements that commenced in 2017 will continue in 2018 driving improvements in the health, patient experience, and safety of the patients seen in the ambulatory practices.

\section{Steven Spencer, MD, MPH}

Medical Director of Population Health

Jefferson Community Physicians

Steven.Spencer@Jefferson.edu improve in all metrics with breast cance screening, colorectal screening, and fall risk being a few of the standouts.

\section{REFERENCES}

1. Centers for Medicare and Medicaid Services. Center for Clinical Standards and Quality. CMS Measure Development Plan 2018 Annual Report. May 3, 2018. https://www.cms.gov/Medicare/Quality-Payment-Program/Measure-Development/2018-MDP-annual-report.PDF. Accessed Oct. 5, 2018.

2. Centers for Medicare and Medicaid Services. Center for Medicare and Medicaid Innovation. 2017 CPC+ Implementation Guide: Guiding Principles and Reporting. May 10, 2017.

3. Centers for Medicare and Medicaid Services. Center for Medicare and Medicaid Innovation. 2018 CPC+ Implementation Guide: Guiding Principles and Reporting. January 30, 2018

\section{An ACE for South Philly Acute Care for the Elderly (ACE) unit makes all the difference at Methodist Hospital}

Older adults are incredibly vulnerable in the acute hospital setting. Bedrest orders or concerns regarding mobility often keep older adults in bed for much of their hospital stay. The challenges of incontinence leave them susceptible to the use of catheters and thus infections or skin breakdown. Their frailty and poor nutrition puts them at risk for injury. An acute hospital stay can be devastating to older adults, leaving them debilitated and at increased risk for falls, and sometimes hastening the need for placement in a skilled nursing facility or nursing home.

In 2011, the leadership at Methodist Hospital, in South Philadelphia took note that the hospital was treating an increasing number of older adults. After 3 years of visiting other hospital systems and attending geriatric conferences to research best practices, the Acute Care of the Elderly (ACE) Unit at Methodist was born. The ACE Unit is dedicated to geriatric patients (over the age of 65) and offers care provided by teams that have been specially trained to meet the unique needs of this population. With strong support from hospital administration, a passionate team of nurses work collaboratively with nursing assistants, physical and occupational therapists, physicians, physician assistants, case managers and a geriatric nurse practitioner, to address geriatric syndromes while simultaneously treating acute medical issues. Now, almost four years after its inception, certificates of excellence line the walls as a testament to the outstanding quality of care that is delivered.

Focused on socialization and mobilization, ACE units are designed to prevent functional decline and related complications in older adults admitted to the hospital for an acute event. Patients admitted to ACE units have been found to experience fewer falls, less delirium, less functional decline at discharge, shorter length of hospital stay, lower costs and more discharges directly to home, as opposed to a nursing home.
On Methodist's ACE unit, the staff encourage patients to move as much as they are able, supervising walks in the halls, and helping them to the bathroom when needed, all with the goal of being able to return home. The importance of maintaining an older person's mobility and function cannot be overstated. Nurses and nursing assistants motivate patients through visual measurements on the wall to track distance and encourage patients to have lunch together in a communal parlor. Socialization and ambulation, which are cornerstones of the program, not only help maintain strength and balance but have a significant impact on preventing confusion that can frequently happen to older adults in the hospital. When possible, catheters are avoided so that patients can be given the opportunity to use the toilet and increase their strength and mobility. Each patient has a bed or chair alarm on and are reminded often to call so that they do not ambulate alone. Nursing staff keep highly vigilant 
about their care and progress in the hospital and give the geriatric team time to focus on issues specific to older adultsnotably skin integrity, mobility, cognition, sleep, bowel and bladder, and nutrition.

The results have been outstanding. Patients admitted to the ACE unit experience fewer hospital-related complications and tend not to stay admitted as long as a regular hospital unit. Patient satisfaction scores are around $90 \%$ and rank among the highest in the hospital. The idea to keep communitydwelling older adults active while hospitalized has paid off for patients, who experience fewer complications, and for the staff, who are consistently satisfied with the autonomy they have in their practice and ability to make nursing care decisions. The care sounds revolutionary, but feels part of the everyday culture on the ACE unit.
Jefferson Methodist Hospital is a NICHE designated organization. NICHE, which stands for Nurses Improving Care for Healthsystem Elders, is a nursing education and consultation program designed to improve geriatric care in healthcare organizations. Aside from the ACE unit, geriatric resource nurses on other hospital units can use their training to advocate for appropriate care for each older adult. Given the increase in the proportion of older adults in the US population, hospitals will undoubtedly be making changes to care for this population. An ACE unit has proven to be a great resource in this endeavor. Older adults deserve nothing less.

\section{Lori Bellizzi, MSN, CRNP}

Nurse Practitioner

ACE Unit, Palliative Care, Geriatrics

Jefferson Methodist Hospital

Lori Bellizi@Jefferson.edu

\section{JCPH 2018 AWARDS}

\section{Outstanding MPH Student Achievement \\ John "Jack" King \\ Brandon Horvath \\ Rachel Vecchione}

\section{Student Service}

Madeline Brooks, MPH Program

Saheedat Sulaimon, MPH Program

Eric Toppy, Health Policy

\section{Outstanding Alumni}

Kate Fox, MPH

\section{Outstanding Online Achievement \\ Elizabeth Woodford, Health Policy \\ Simon Lam, Applied Health Economics and Outcomes Research}

\section{Faculty Achievement}

Martha Romney, MS, RN, JD, MPH

Distinguish Mentor

Vittorio Maio, PharmD, MS, MSPH

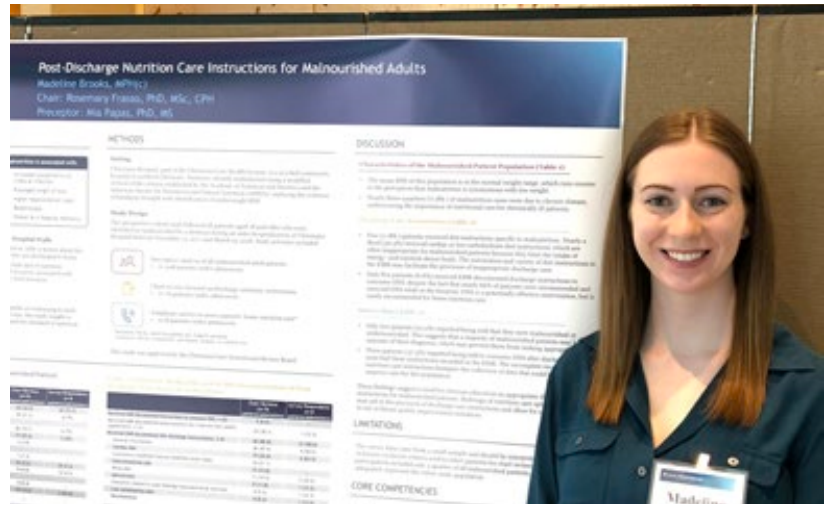

Madeline "Maddie" Brooks received the MPH Student Service Award

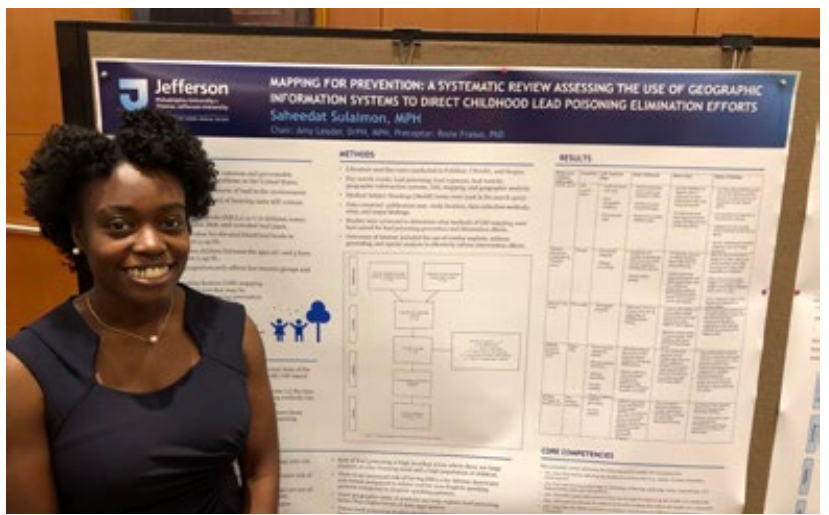

Sadeedat Sulaimon received the MPH Student Service Award 


\section{Meet the JCPH Health Economics Outcomes Research (HEOR) Fellows}

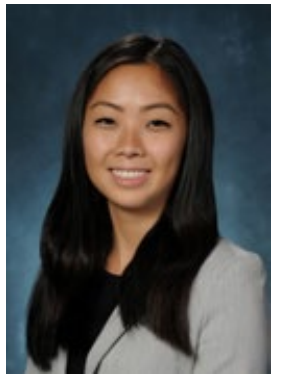

Arianna Kee, PharmD

Arianna Kee is a

post-doctoral HEOR

Fellow at Thomas

Jefferson University.

She received her

PharmD from the

Ernest Mario School of

Pharmacy at Rutgers

University where

her early research focused on studies in targeted drug delivery and cancer drug development. As she progressed through pharmacy school, she began to utilize her clinical knowledge to conduct economic and real-world evidence evaluations at Robert Wood Johnson University Hospital. She led protocol development, data management and analysis, and dissemination of results at national conferences. Her interest in HEOR and understanding of the essential role it plays in healthcare was further reinforced through her involvement in Academy of
Managed Care Pharmacy (AMCP) and the P\&T competition. She evaluated literature to build a value proposition and generated a coverage position to defend it before leaders in managed care and the pharmaceutical industry. Arianna then translated her experience into practice at McCann Managed Markets where she worked with industry clients to identify and fill gaps in value propositions to better meet payer needs. As a post-doctoral HEOR fellow at JCPH, she hopes to impact healthcare reform, resource allocation, and patient outcomes while working towards her Master's degree in Applied Health Economics and Outcome Research.

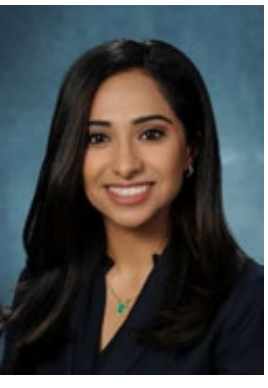

Karishma Shelley, PharmD

Karishma received her Doctor of Pharmacy degree from The University of The Sciences (USciences) in 2018. Karishma's interest began at Express Scripts, a

pharmacy benefit management company. During this internship she had the opportunity to lead a cross-functional team to identify gaps in the formulary decisions practice for a Department of Defense contract. The impact of real-world evidence and outcomes research on formulary decisions stimulated her interest in HEOR. Her interest in realworld evidence led her to co-author a review article on the real-world implementation of HIV pre-exposure prophylaxis. Karishma is excited to be part of the Jefferson family and learn necessary skills to devise outcomes research that impacts patients' access to care.

\section{For more information on the HEOR Fellow, join our webinar, Nov. 1, 2018, 7:00 PM ET.}

\section{http://bit.ly/JCPHHEORWebinar}

\section{What's Next for Population Health Matters?}

Starting with the Winter 2019 Issue of Population Health Matters, you'll be seeing some changes to the newsletter.

We'll be kicking off the New Year with an updated e-newsletter format, featuring breaking JCPH news items, student and faculty highlights, and thought pieces on emerging issues. This format will replace what you have previously received as a subscriber (i.e. PDF \& flip book).

If you're already a subscriber, you don't need to do anything. The newsletter will be sent via email.

If you don't already subscribe, visit: https://www.jefferson.edu/ university/population-health/contact_me.html.html.

As always, you may email us at jcphnewsletter@jefferson.edu with your ideas, stories, and feedback.

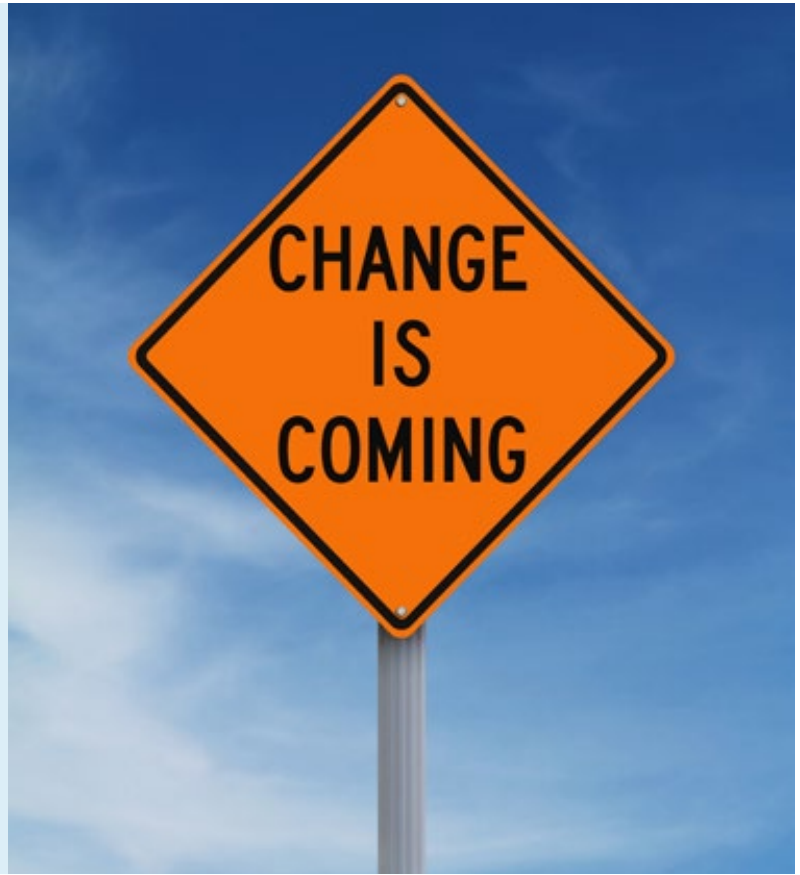




\section{IN THE NEWS}

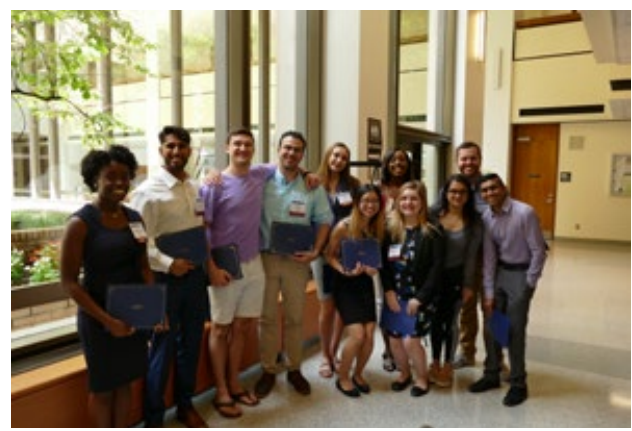

MPH Student Ambassadors!

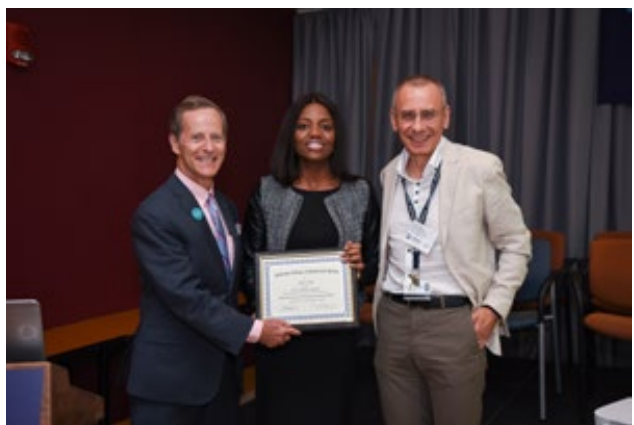

Lauren Djatche, PharmD (Novartis) completed the HEOR Fellowship program.

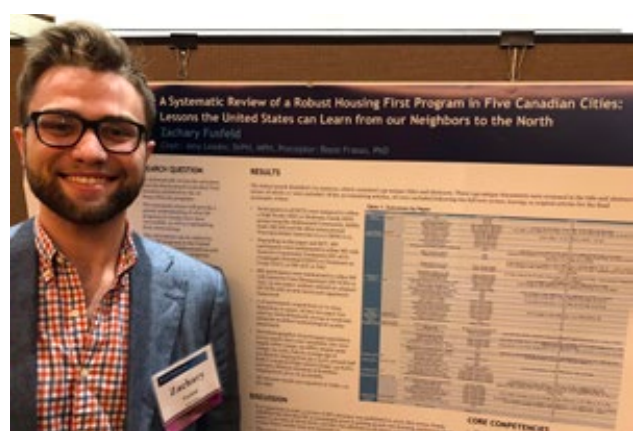

Zachary Fusfeld at the MPH Capstone Symposium

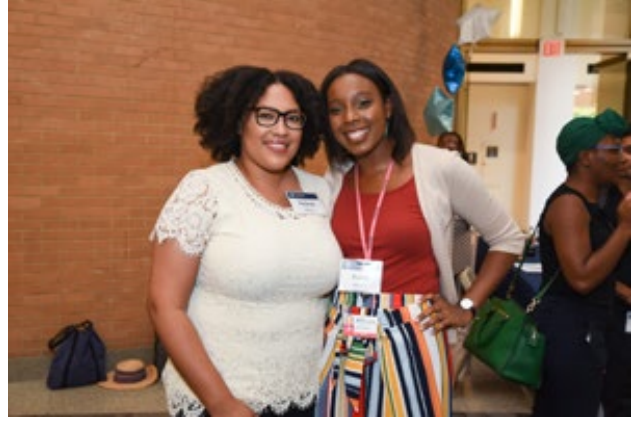

Current MPH students Nichole Holmes (left) and Kaéla Edwards (right) are there to welcome new student at the MPH student orientation.

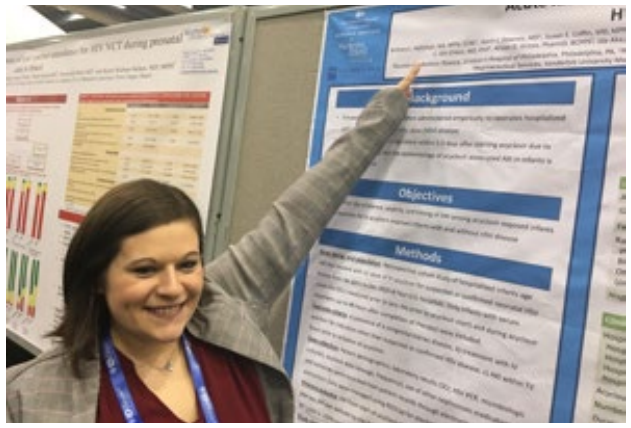

JCPH Alumni Brittany Halzman, MS, MPH, CCRC presented at the Infectious Diseases Society of America IDWeek.

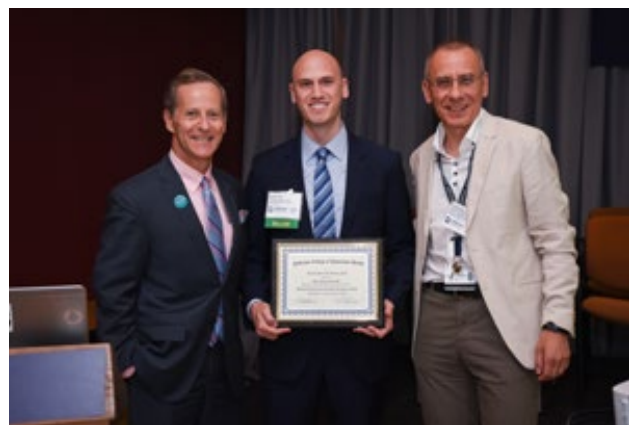

David Singer, PharmD (Janssen) completed the HEOR Fellowship program.

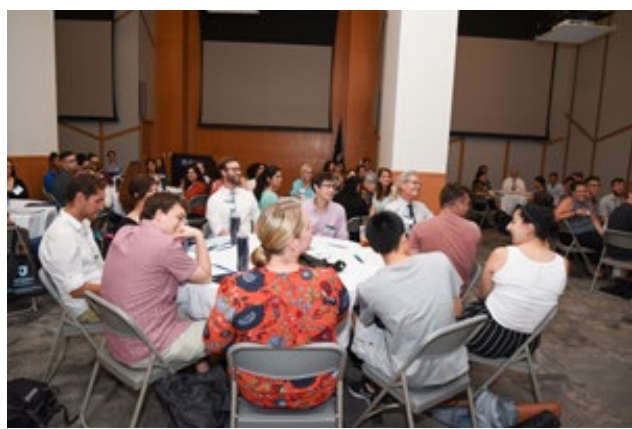

2018 MPH Student Orientation

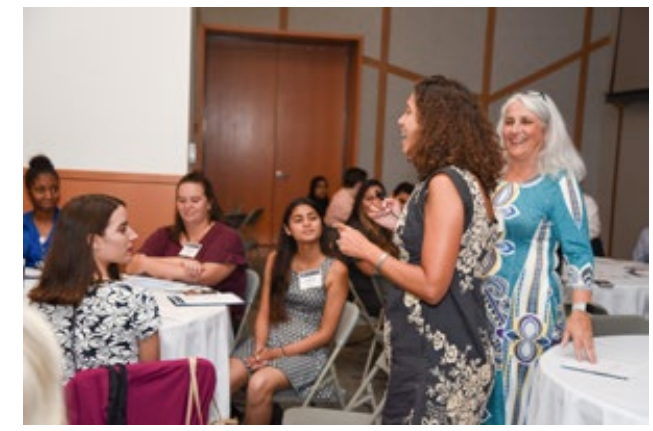

Dr. Frasso introduces Associate Professor Amy Leader, DrPH, MPH at the MPH student orientation

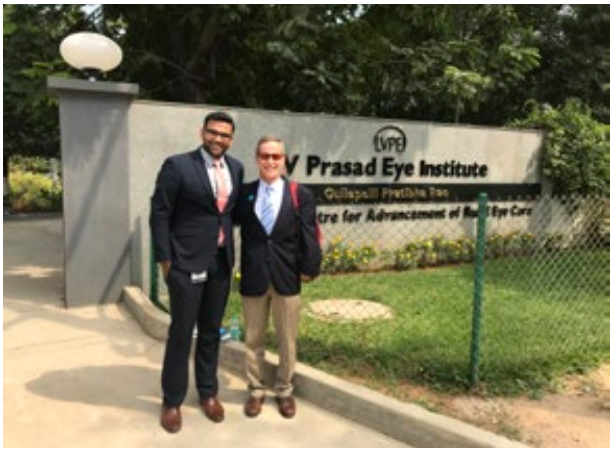

MPH Alumni and Global Affairs Research Associate Parth Lalakia traveled with Dean Nash to Hyderabad, India to visit LVPEI where Dr. Nash presented on population health.

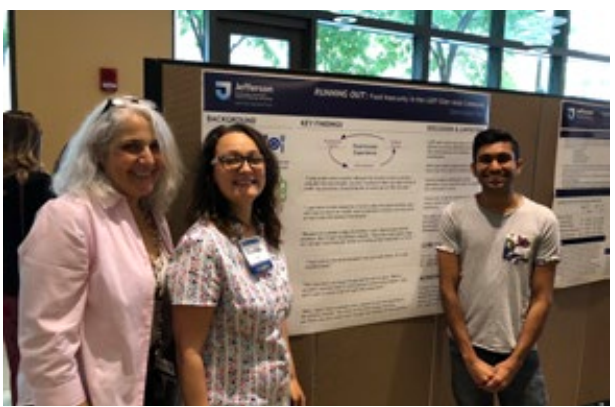

MPH Program Director, Rosemary

"Rosie" Frasso, PhD, CPH at the capstone symposium with students Dominque Viola and Ambuj Suri

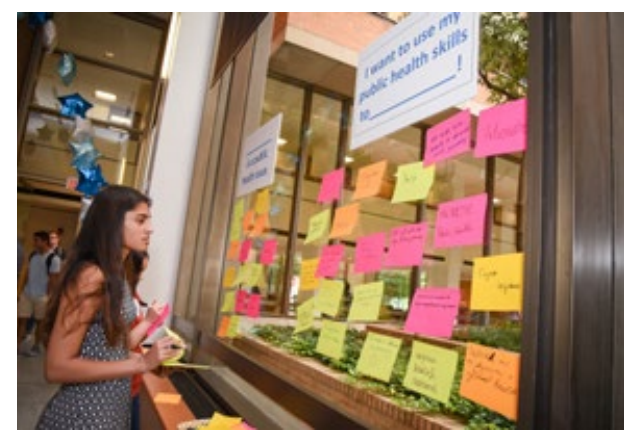

Incoming MPH student Pankti Acharya at MPH student orientation

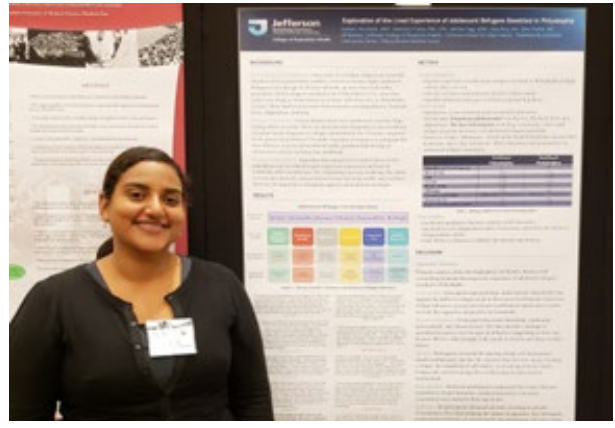

Recent grad Pia Ghosh, MPH presented at the International Conference on Migration Health in Rome! 


\section{IN THE NEWS}

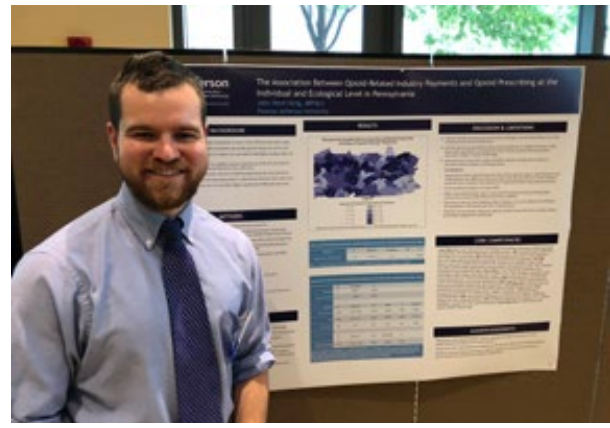

John "Jack" King was recognized for Outstanding MPH Student Achievement

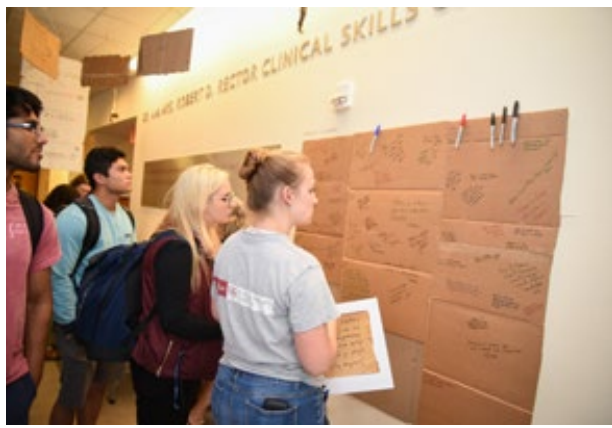

Signs of Humanity Exhibition and Reception

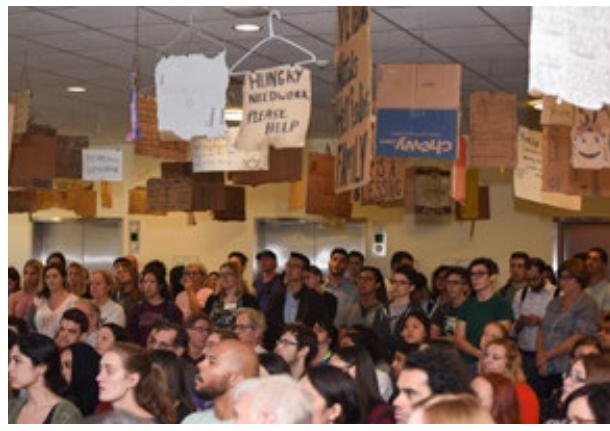

Signs of Humanity Audience

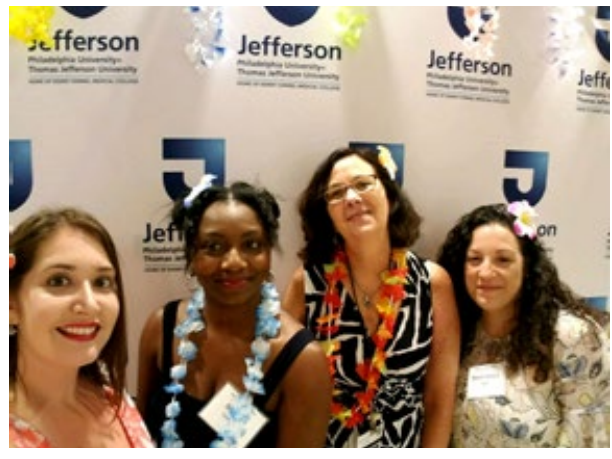

From left to right: Vivian Castillo, Mariah Carpenter, Emily Frelick, and Marygrace Cacia at the JCPH 10th Anniversary.

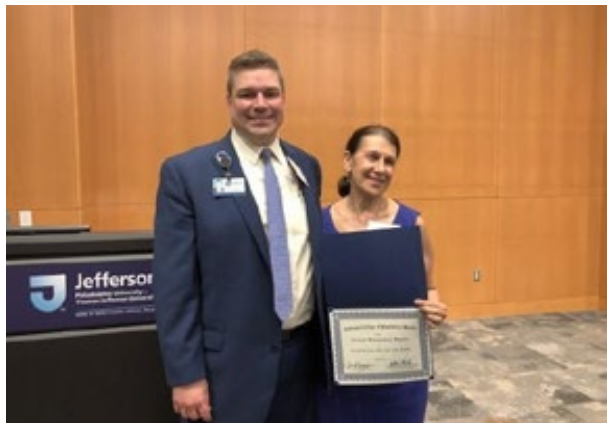

Martha "Marty" Romney MS, RN, JD, MPH received the JCPH Faculty Achievement Award

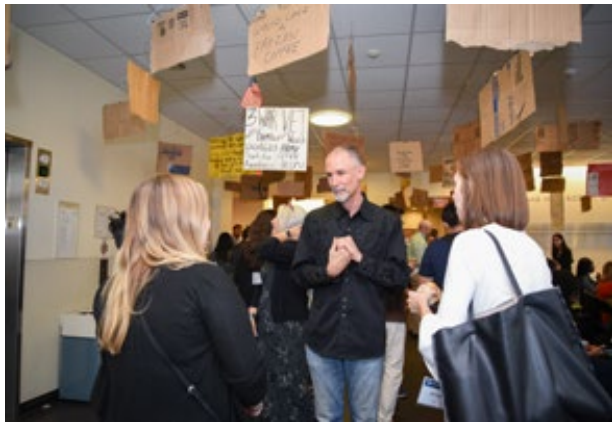

Artist Willie Baronet at Signs of Humanity Exhibition and Reception

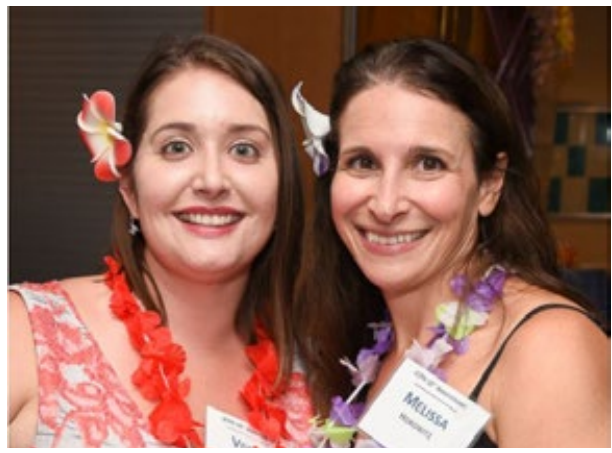

Vivian Castillo (left) and Melissa Horowitz (right) at the JCPH 10th Anniversary Party.

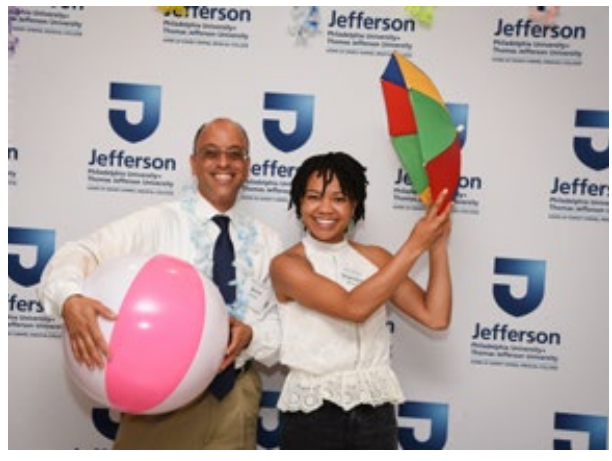

JCPH 10th Anniversary Party with David Delgado and Dominique Medaglio

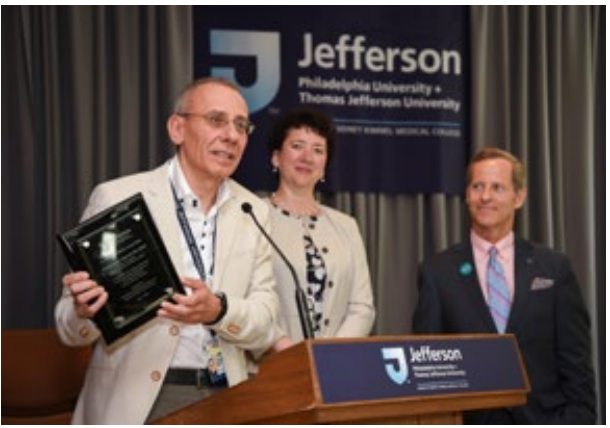

Vittorio Maio, PharmD, MS, MSPH received Thomas Jefferson University's Distinguished Mentor Award. Watch Dr. Maio.

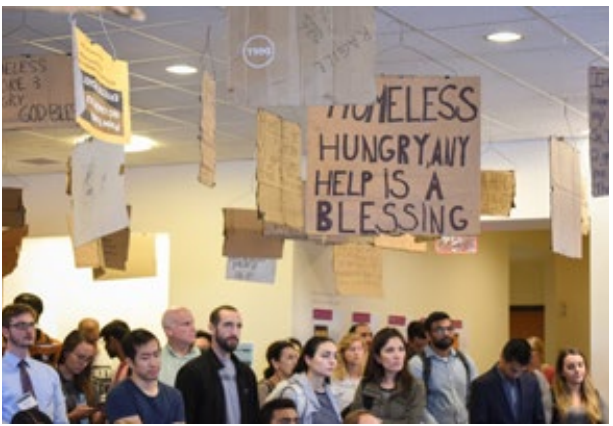

Signs of Humanity Audience

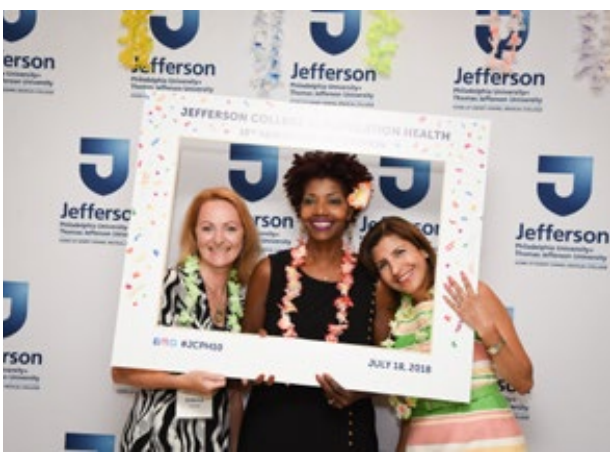

JCPH 10th Anniversary Party (left to right): Jennifer Aylmer, Zita Jackson and Elizabeth DeBonis 
Dress EM, Frasso R, Calkins ME, Curry $A E$, Kohler CG, Schmidt LR, Sisti DA, Comparing patient, clinician, and caregiver perceptions of care for early psychosis: A Free Listing Study." Narrative Inquiry in Bioethics. 2018;8(2):157-

178. Project MUSE, doi:10.1353/ nib.2018.0054

Gangemi K, Dupuis R, Fitzgerald E, Frasso R, Solomon S, Cannuscio CC. Youth speak out on school food environments. J Sch Nursing. 2018; Oct 4:1059840518800777. doi: 10.1177/1059840518800777. [Epub ahead of print].

Harris D, McCormick CM, Opening the healthcare profession pipeline for every student in Philadelphia. The Inquirer. September 25, 2018.
Leader A, Cognetti D. Commentary: parents are missing an opportunity to protect their children from some cancers. The Inquirer. September 10, 2018.

Mohanty S. Leader AE, Gibeau E, Johnson C. Using facebook to reach adolescents for human papillomavirus (HPV) vaccine. Vaccine. 2018;36(40):5955-5961/

Nash DB. Are Accountable Care Organizations saving money or not? Medpage Today. September 21, 2018

Nash DB. Quality know no bounds. Medpage Today. August 17, 2018.

Patel N, Vemuri D, Frasso R, Brennan PJ, Myers JS. Perceptions of health care executives on leadership development skills for residents after participating in a longitudinal mentorship program. Am J Med Qual. First published July 16, 2018. https://doi. org/10.1177/1062860618786798

Rising KL, LaNoue MD, Gerolamo AM, Doty ABM, Gentsch AT, Powell RE. Patient uncertainty as a predicator of 30-day return emergency department visits: an observational study. Acad Emerg Med. First published September 23, 2018. https://doi.org/10.1111/acem.13621

VonHoltz LAH, Frasso R, Golinkoff JM, Lozano AJ, Hanlon A, Dowshen N. Internet and social media access among youth experiencing homelessness: mixedmethods study. J Med Internet Res. 2018; 20 (5):e184:1-10.

\section{JCPH PRESENTATIONS}

Borum Chattoo C, Feldman L,

Riley AH. From reality to drama: The role of entertainment TV storytelling in empowering U.S. Hispanic parents. Presented at: Association for Education in Journalism and Mass Communication, August 6, 2018, Washington, D.C.

Frasso R. Qualitative methods: Understanding stigma and exploring mental health. Presented at: University of Shijiazhuang, June 7, 2018, Shijiazhuang, China.

Frasso R. Qualitative methods: Understanding stigma and exploring mental health. Presented at Pen Wharton China Center, June 7, 2018, Beijing, China.
George B. Double time: Integrating online learning tools with a flipped classroom in a public health statistics course. Presented at: Joint Statistical Meetings, July 31, 2018, Vancouver, British Columbia, Canada.

Harris D. Douglas K. Parks in a Truck. Presented at: "Fast Forward" Design Philadelphia, DATE, Philadelphia, PA.

Harris D. AARP Pennsylvania Housing, Design, and Health Panel Discussion at 2018 DesignPhiladelphia Conference, October 9, 2018, Philadelphia, PA.

Maio V. From inappropriate prescribing to deprescribing: tools and methodologies. Presented at: Prescribing for the Elderly: Between Ageism and Choosing Wisely Conference, University Hospital S. Maria Nuova, June 22, 2018, Reggio Emilia, Italy.
Olgesby WH, Nash DB. Developing and accreditation framework for graduate programs in healthcare quality and safety. Podium presentation at: ISQua's 35th International Conference, September 2018, Kuala Lumpur, Malaysia.

Crisp H, Oglesby WH, Woodhead T, Vign TW, Eljiz K. Who needs quality improvement training? Podium presentation and debate at ISQua's 35th International Conference, September 2018, Kuala Lumpur, Malaysia.

Skoufalos A. Stakeholder collaboration: how can the private and public sectors work together to reverse social isolation? Panel discussion (moderator) at 2018 Connectivity Summit on Rural Again, Reversing Social Isolation, August 7-9, Portland, ME. 


\section{Population Health Matters}

Jefferson College of Population Health

Thomas Jefferson University

901 Walnut Street, 10th Floor

Philadelphia, PA 19107

\section{EDITORIAL BOARD}

\section{Editor}

\section{David B. Nash, MD, MBA}

Dean

Jefferson College of Population Health

\section{Managing Editor}

Emily J. Frelick, MS

Senior Project Director

Jefferson College of Population Health

\section{Editorial Board}

\section{Lauren Collins, MD}

Associate Director, Jefferson Center for InterProfessional Education

Director, Jefferson Health Mentors Program Assistant Professor

Division of Geriatric Medicine

Department of Family and

Community Medicine

Sidney Kimmel Medical College
Michael Dryer, DrPH, PA-C

Executive Dean for College of Science,

Health and the Liberal Arts

Thomas Jefferson University,

East Falls Campus

Rosemary Frasso, PhD, MSc, CPH

Program Director, Public Health

Associate Professor

Jefferson College of Population Health

Max Koppel, MD, MBA, MPH

Clinical Associate Professor of Urology

Department of Urology

Thomas Jefferson University

Juan Leon, PhD

Director of Online Learning

Jefferson College of Population Health

Mary Lou Manning, PhD, CRNP,

CIC, FAAN

Associate Professor

Jefferson College of Nursing

\section{Ronald E. Myers, PhD, DSW}

Professor

Director of the Division of Population Science

Department of Medical Oncology

Sidney Kimmel Medical College

Billy Oglesby, PhD, MSPH, FACHE

Associate Dean for Academic and

Student Affairs

Jefferson College of Population Health

\section{Shoshana Sicks, EdM}

Administrative Director

Jefferson Center for InterProfessional

Education

\section{Randa Sifri, MD}

Professor

Director of Research

Director, Research Fellowship

Co-Director, Postdoctoral Fellowship

Family and Community Medicine

Thomas Jefferson University

\section{Alexis Skoufalos, EdD}

Associate Dean for

Strategic Development

Executive Director

Center for Population Health Innovation Jefferson College of Population Health

\section{Rachel Sorokin, MD}

Chief Patient Safety and Quality Officer Thomas Jefferson University Hospital

Steven Spencer, MD, MPH, FACP

Director of Population Health Abington Health Physicians Jefferson Health

Richard G. Stefanacci, DO, MGH, MBA, AGSF, CMD

Lecturer, Jefferson College of

Population Health

Chief Medical Officer, The Access Group
901 Walnut Street, 10th Flr. Philadelphia, PA 19107 